\title{
Refining the Role of Lgl, Dlg and Scrib in Tumor Suppression and Beyond: Learning from the Old Time Classics
}

\author{
Fani Papagiannouli ${ }^{1}$ and Bernard M. Mechler ${ }^{2,3,4}$ \\ ${ }^{1}$ Cell Networks-Cluster of Excellence, Centre for Organismal Studies (COS) and \\ BIOQUANT Center, University of Heidelberg, Heidelberg, \\ ${ }^{2}$ Department of Cell Biology, Institute of Physiology, $1^{\text {st }}$ Faculty of Medicine, \\ Charles University, Prague, \\ ${ }^{3}$ Deutsches Krebsforschungszentrum, Heidelberg, \\ ${ }^{4}$ VIT-University, Vellore, Tamil Nadu, \\ 1,3Germany \\ ${ }^{2}$ Czech Republic \\ India
}

\section{Introduction}

In the course of the $20^{\text {th }}$ century the fruit fly Drosophila melanogaster became one of the most studied metazoans and, as all other members of this family, flies can be afflicted by various forms of neoplasia. Pioneering studies in the field of Drosophila, mouse somatic cells and human genetics revealed about 40 years ago that cancer development may develop from loss of function in regulatory genes controlling cell growth and differentiation (Gateff and Schneiderman 1969, Gateff 1974, Harris et al. 1969, Knudson 1971). The discovery of mutations causing neoplasia during Drosophila development (Gateff 1978) has revealed that cell polarity is significantly affected in the tumor cells. Application of molecular biology for the study of genes controlling Drosophila development led to the isolation and characterization of the first tumor suppressor gene (TSG), the lethal (2) giant larvae (lgl) (Mechler, McGinnis and Gehring 1985) and consequently placed Drosophila at the center of cancer research. $\lg l$ encodes a cytosolic protein with two WD40 motifs, involved in proteinprotein interactions (Wodarz 2000). Lgl can bind to non-muscle myosin II and to the cytoskeleton matrix, along the baso-lateral portion of the plasma membrane in epithelial cells to affect cell polarization (Jakobs et al. 1996, Strand et al. 1994a, Strand, Raska and Mechler 1994b). In addition, Lgl can be a critical factor in the process of steroid-induced cell death during metamorphosis, a process which happens to be independent from the cell polarity function (Farkas and Mechler 2000). Similar to lgl, mutations in discs large-1 (dlg) and scribble (scrib) TSGs can cause tissue overgrowth phenotypes, as homozygous mutations in these genes lead to neoplastic transformation, thereby leading to imaginal disc overgrowth and brain tumors. In these tumors the overproliferating epithelial cells become rounded, rather than polygonal, lose their ability to terminally differentiate and fail to organize an epithelial monolayer (Bilder 2004). $d l g$, scrib and $l g l$ mutants fail to pupariate 
and have a prolonged larval life during which they grow enormously in size and become "giant", bloated and transparent (Papagiannouli 2003). Further analysis revealed defects in apical-basal polarity, followed by loss of epithelial structure; therefore, all three TSGs are classified also as "cell polarity genes" (Wodarz 2000, Woods et al. 1996, Bilder and Perrimon 2000, Li et al. 2001). Dlg is a protein of the MAGUK (membrane - associated guanylate kinases) family, which consists of a class of scaffolding proteins that recruit signaling molecules into localized multimolecular complexes. Dlg localizes at the cytoplasmic side of septate junctions between adjacent epithelial cells, as well as in neuromuscular junctions. It contains 3 PDZ domains involved in protein-protein interactions with membrane or cytoskeletal proteins, an SH3 domain and a GUK domain. The Scrib protein is also a septate junctional protein of the LAP family (Bryant and Huwe 2000), containing four PDZ domains and leucine-rich repeats (LRRs) (Bilder 2001, Wodarz 2000, Mathew et al. 2002) thought to be involved in Ras signaling (Humbert, Russell and Richardson 2003).

The Dlg, Scrib and Lgl proteins are highly conserved in sequence among different species and growing evidence suggests that they are functionally conserved to a large degree since the vertebrate homologues can rescue the polarity defects and tumorous overgrowth of the respective Drosophila mutants (Thomas et al. 1997b, Grifoni et al. 2004, Dow et al. 2003). There are four well characterized mammalian Dlg members: Dlg1 (hDlg/SAP97), Dlg2 (PSD-93/Chapsyn-110), Dlg3 (NE-Dlg/SAP102) and Dlg4 (PSD-95/SAP90). All display the characteristic MAGUK structural domains of the Drosophila homologue, are involved in polarity establishment and are dysregulated in several cancer lines. There are also two Lgl (Lg11/Hugl1 and Lg12/Hugl2) mammalian homologues and only one single Scrib homologue in higher vertebrates. The human Scrib (hScrib) gene shows high homology to the Drosophila Scrib and colocalizes with Dlg family members (Humbert et al. 2003). Similarly, loss or alterations in expression of $d l g$, scrib and $l g l$ in humans are correlated with more invasive and aggressive tumors (Humbert et al. 2003, Gardiol et al. 2006, Brumby and Richardson 2003, Nakagawa et al. 2004).

\section{Tumor suppressors as multitasking proteins}

Over the last decades, further work revealed that junction complexes are not just static barriers, limiting the diffusion of proteins along of the cortical cell domains, but have a broader function. As polarity scaffolds are nowadays considered as dynamic organizing centers of site-specific protein targeting or exclusion from adjacent domains that provide guiding cues for signaling molecules and targeted membrane insertion (Lecuit and Wieschaus 2002), studying these classical tumor suppressors in other tissue contexts has gained new interest (Papagiannouli and Mechler 2010). Recent advances in the diverse functions of $d l g$, scrib and $\operatorname{lgl}$ have defined them as key players in numerous tissues contents and malignancies at different time points throughout development; furthermore, they have revealed their multitasking role in: 1) junction and cytoskeleton establishment, epithelial cell and planar cell polarity, 2) asymmetric neuroblast division, formation of synapses and neuromuscular junctions, nervous system and brain development including memory (Moreau et al. 2010, Chen et al. 2008) and olfaction (Ganguly, Mackay and Anholt 2003, Mao et al. 2008), 3) testis, ovaries and other organ development, 4) cancer initiation, progression and metastasis and 5) mechanism of cooperation with various signaling pathways in different tissue contexts (Ras, SWH, Dpp, JNK, Wg, Egfr etc) (Figure 1). These new and 
unexpected findings show that Dlg, Scrib and Lgl are dynamic cytoskeletal components which affect epithelial cell structure, polarity and growth behavior by directing the trafficking of proteins to proper plasma membrane surfaces of the cell and by organizing and stabilizing supramolecular adhesion and signaling complexes through their action as scaffolding adaptor molecules (Woods et al. 1996, Bilder, Li and Perrimon 2000, Harris and Lim 2001, Goode and Perrimon 1997, Lee et al. 2003, Gorczyca et al. 2007, Mahoney et al. 2006, Thomas et al. 2000, Chen and Featherstone 2005, Bilder 2001, Humbert et al. 2003).

\subsection{Tumor suppressors in polarity establishment and functional cooperation with other polarity and signaling complexes}

Epithelial cells are polarized, with apical and baso-lateral domains. These domains are characterized by different components: outer-membrane, trans-membrane and innermembrane proteins. A belt of adherens junctions (AJs) forming the zonula adherens (ZA) separates the apical domain of the cell membrane from its baso-lateral domain. The ZA complex consists of E-cadherin (E-cad), a-catenin, and Armadillo (the Drosophila $\beta$-catenin), and serves as a contact interface between neighboring cells and the cytoskeleton. Apically located components include the "Par-complex" consisting of Bazooka/Par3 (multi-PDZ containing protein), Drosophila atypical protein kinase C (aPKC), and DmPAR6 (a singlePDZ containing protein) and the "Crumbs-complex" consisting of Crumbs (a transmembrane protein) and Stardust (a MAGUK protein). The septate junctions are situated in a region underneath the $\mathrm{ZA}$, serve as a barrier, limiting the diffusion of membrane proteins and separate the apical from the basal components. In septate junctions the "Dlg-complex" includes Dlg, Scrib, and Camguk (Cask or Lin2, a MAGUK protein) (Mathew et al. 2002, Humbert et al. 2003), whereas the Lgl protein accumulates at the baso-lateral cortical matrix. In vertebrates the septate junctions are replaced by tight junctions, which are apical rather than basal to the adherens junctions and are composed of two integral membrane proteins, the Occludins and Claudins, and the proteins of the MAGUK family ZO-1, ZO-2 and ZO-3. In the Drosophila embryonic epidermis, mutations in $d l g$, scrib or lgl cause leakage of the apical protein Crumbs (Bilder et al. 2000, Bilder and Perrimon 2000). crumbs overexpression induces expansion of the apical domain and affects the formation of AJs (Wodarz et al. 1995, Grawe et al. 1996), similar to the scrib mutant phenotype (Bilder and Perrimon 2000), suggesting that laterally located tumor suppressor proteins regulate apical membrane polarity. Genetic analysis revealed antagonistic interactions between the apical Crumbs- and the lateral Dlg-complex, as crumbs and stardust mutants are rescued by mutations in $\mathrm{dlg}$, scrib or $\mathrm{lgl}$ (Bilder, Schober and Perrimon 2003, Tanentzapf and Tepass 2003). Crumbs has one cytoplasmic motif that links it to the spectrin and actin cytoskeleton and one that interacts with polarity-regulatory factors such as Par6 and Stardust (Bulgakova and Knust 2009). The Par-complex plays a critical role in this antagonistic interaction (Humbert, Dow and Russell 2006), as it restricts the Crumbs-complex apically, and the Par- and Crumbs- complexes act together to exclude the Dlg-complex from the apical membrane (Humbert et al. 2006, Bilder et al. 2003, Tanentzapf and Tepass 2003). This spatial segregation is facilitated by a biochemical interaction between the Scrib and Par complexes through Lgl (Hutterer et al. 2004, Plant et al. 2003, Yamanaka et al. 2003, Betschinger, Mechtler and Knoblich 2003, Langevin et al. 2005). Moreover, in the Drosophila ectoderm, phosphorylation of aPKC is required for $\mathrm{Lgl}$ to establish the lateral domain and to prevent apical Lgl recruitment (WirtzPeitz and Knoblich 2006, Hutterer et al. 2004). 
In Xenopus, Lg12 and aPKC act antagonistically to mutually regulate their localization and the establishment of apical-basal polarity in blastomeres (Chalmers et al. 2005). In MardinDarby Canine kidney (MDCK) epithelial cells, studies of overexpression and RNAi-induced loss of function revealed that $\mathrm{Lgl}$ facilitates the establishment of apical-basal polarity through actively suppressing the formation of the Par-complex formation at the basal domain (Humbert et al. 2006, Yamanaka et al. 2003, Yamanaka et al. 2006). In zebrafish, Lgl2 mutants show an epithelial-to-mesenchymal transition in basal epidermal cells, with loss of hemidesmosome formation and an increase in migratory behavior (Sonawane et al. 2005). At the same time, Lgl2 positively regulates hemidesmosome formation by mediating Integrin alpha 6 (Itga6)-targeting and maintaining its localization, while E-cad negatively regulates Itga6 targeting (Sonawane et al. 2009). Localization of aPKC $\lambda$ in the basal epidermis is tightly correlated with Itga6 localization and hemidesmosome formation (Sonawane et al. 2009). The role of Lgl and the Par-complex was also analyzed in the polarity establishment of the early C. elegans embryo, where they maintain two cortical domains which are sufficient to partition cell fate determinants in the C. elegans embryo, by a mechanism of "mutual exclusion" (Hoege et al. 2010). Lgl1 interacts with Par-2 in the posterior of the embryo, but Lgl1 can also compensate the function of Par-2 and restrict the anterior localization of the Par-complex, through a mechanism that involves Lgl phosphorylation (Hoege et al. 2010) and a negative regulation of non-muscle myosin-II at the posterior cortex (Beatty, Morton and Kemphues 2010)

Of particular interest are studies that relate the adenomatous polyposis coli (APC) tumour suppressor to the mammalian Dlg homologues. Dlg1 was isolated in a yeast-two-hybrid screen and was found to directly interact with APC (Humbert et al. 2003, Ishidate et al. 2000). Dlg3 also binds APC, thereby showing that this interaction is probably a common feature of Dlg family members. In the migrating astrocytes, vertebrate Dlg1 binds APC at the leading edge of migrating cells (Etienne-Manneville et al. 2005). In particular, activation of the Par6-PKC $\zeta$ complex by Cdc42, at the leading edge of migrating cells, promotes the localized association of APC with microtubule plus ends and the assembly of Dlgcontaining puncta in the plasma membrane. Scrib also binds APC (Takizawa et al. 2006). As $\mathrm{Dlg}$ and Scrib can bind the Wnt signaling component APC, one could hypothesize that loss of Scrib or Dlg could interfere with the normal regulation of the APC- $\beta$-catenin complex, thereby leading to pro-migratory effects, if $\beta$-catenin is stabilized and allowed to move to the nucleus (Humbert et al. 2006).

In addition, Dlg, Scrib and Lgl play an important role in dorsal closure (DC), during which, the migration of the lateral epidermal leading edge (LE) cells closes the hole of the Drosophila dorsal epidermis. Loss of $l g l$ results in defective DC (Manfruelli et al. 1996, Arquier et al. 2001) and loss of scrib together with one allele of $d l g$ also results in incomplete DC (Bilder et al. 2000). Recent studies have shown that during DC the LE cells undergo a mesenchymal-to-epitheliallike transition, during which integrin-mediated localization of the PAK serine/threonine kinase recruits Scrib in septate junction formation, required for epithelial plasticity (Bahri et al. 2010). Wound healing is very similar to the DC in Drosophila and Scrib is here again a critical player in the polarization of migrating cells. During wound healing in the astrocytes, Scrib controls Cdc42 through its association with the exchange factor $\beta$ PIX (Osmani et al. 2006). By regulating Cdc42 activity, Scrib acts upstream of Dlg1 and is involved in the same molecular pathway controlling cell orientation. Cdc42 controls two distinct signaling pathways, promoting: 1) Rac- and PAK-dependent protrusion formation and 2) centrosome and Golgi reorientation through APC clustering and Dlg1 localization at the LE (Osmani et al. 2006). 
The role of Dlg, Scrib and Lgl has also been studied in other tissue - specific epithelia. Dlg-1 and Scrib are widely distributed throughout the eye in embryonic and postnatal development and overlap with E-cad and ZO-1 in portions of the cornea and retinal pigment epithelium; in contrast, little, if any, overlap with adhesion proteins is observed in the neural retina (Nguyen, Rivera and Griep 2005). Dlg1 was shown to be required for the development of lens epithelium in a cell autonomous manner as Dlg1 ablation leads to cell structure alterations and disposition of adhesion and cytoskeletal factors such as $\alpha$-catenin (Rivera et al. 2009). In the intestinal epithelium, Scrib regulates the integrity and plasticity of the epithelial barrier and TJ formation, by binding to the scaffolding protein ZO-1, independently of Lgl1 and Dlg1. The observation that Scrib is downregulated during intestinal inflammation provides the missing link to tumor development during chronic intestinal inflammation (Ivanov et al. 2010). Dlg1 localization at the basolateral side of the intestinal epithelium requires CASK, another MAGUK protein, however dlg1 mutations there cannot affect epithelial polarity (Lozovatsky et al. 2009). Data from the C. elegans intestinal epithelium show that Arp2/3, which promotes nucleation of branched actin, junction initiation and maturation, affects the subcellular distribution of Dlg (Bernadskaya et al. 2011).

Dlg, Scrib and Lgl are also important in follicular epithelium morphogenesis and subsequent polarization of the Drosophila oocyte, albeit in a different way as in other epithelia. The work of several groups has shown that Lgl is an essential regulator of posterior follicle cells and that phosphorylation of Lgl together with Par-1 and Par-3 is required for the posterior translocation of oocyte-specific proteins and germline determinants (Fichelson et al. 2010, Doerflinger et al. 2010, Li et al. 2008). Mutation of the aPKC phosphorylation site in Par-1 results in the uniform cortical localization of Par-1 and the loss of cortical microtubules (Doerflinger et al. 2010). Dlg and Scrib are required differentially for patterning in both the anterior and posterior follicular epithelium (Li et al. 2009) and genetically interact with Lgl for posterior follicle cell induction ( $\mathrm{Li}$ et al. 2011), suggesting a common regulatory pathway in this process. At the same time, Lgl functions in a subdivision of anterior follicle cells into functionally distinct subpopulations and controls collective border cell migration at mid-oogenesis (Li et al. 2011).

The multifunctional role of these TSGs can also be seen in the diverse binding partners and regulators in various cell environments. For example, Scrib1 was found to interact with LPP, a zyxin-related protein, which has been described as a partner in fusion proteins associated with different types of cancers (Petit et al. 2005, Lelievre 2010). Both Scrib and LPP localize at cell-cell contacts whereas LPP is also localized in the focal adhesions and the nucleus. This interaction links Scrib to a communication pathway between cell-cell contacts and the nucleus (Petit et al. 2005). A nuclear shuttling mechanism has also been described for Dlg1 (Carr et al. 2009). Mammalian Scrib regulates also E-cad activity by stabilizing E-cad coupling to catenins (Qin et al. 2005). The stability and function of the mammalian Lgl is regulated by direct binding to the scaffolding RanBPM, a Ran-binding protein (Suresh et al. 2010). Moreover, Dlg1, which is highly expressed in embryonic and adult tissues such as the brain, kidney, ovaries, olfactory bulb and cerebellum, can interact with Dlg3 (Mao et al. 2008). In addition, Dlg1 can interact with the gap junction protein Connexin-32 through its SH3 domain (Duffy et al. 2007). Recent work on caspase target genes has provided evidence that Dlg1 is a direct target of caspase- 3 and the unique cleavage site identified separates the C-terminal part of Dlg1 (containing PDZ3, SH3 and GUK domain) from the rest of the 
protein. Interestingly, this exact C-terminal part is missing from the classical null allele $\left(d l^{m 52}\right)$ of the Drosophila Dlg mutant protein (Gregorc et al. 2005). This cleavage of Dlg1 results in translocation away from sites of cell-cell contacts and is presumably an early step in disassembly of septate and adherens junctions and consequently intercellular detachment (Gregorc et al. 2005).

\begin{tabular}{|c|c|c|}
\hline \multirow[b]{2}{*}{$\begin{array}{l}\text { Microtubules (MTs) \& Centrosome } \\
\text { positioning } \\
\text { - In wound-healing astrocytes Cdc42 and Dlg1 } \\
\text { regulate dynein interaction with MTs at the cell front } \\
\text { - Dig1 binds dynein via GKAP and all together regulate } \\
\text { MT dynamics near the cell cortex and at the MT- } \\
\text { organizing center, leading to centrosome positioning } \\
\text { - Dlg1 binds APC at MT-plus ends to regulate MT } \\
\text { polarization and centrosome reorientation }\end{array}$} & \\
\hline & \multicolumn{2}{|c|}{$\begin{array}{l}\text { - In epithelial cells, Dig and Scrib localize either at the Drosophila septate junctions or } \\
\text { - at the vertebrate tight junctions whereas LgI accumulates at the basolateral regions } \\
\text { - Dig, Scrib and LgI (the DIg-complex) regulate apical membrane polarity and act } \\
\text { antagonistically to the apical Crumbs-complex, whereas the Par-and Crumbs- } \\
\text { complexes prevent apical recruitment of the DIg-complex } \\
\text { - LgI homologues genetically interact with Par components to regulate apicobasal } \\
\text { polarity in Xenopus and in MDCK epithelial cells, in partitiong of cell fate } \\
\text { determinants in C.elegans, and regulating hemidesmosome formation in zebrafish } \\
\text { - Dlg and Scrib bind APC, linking the APC- } \beta \text { catenin pathway to carcinogenesis } \\
\text { - Dlg, Scrib and Lgl are required for dorsal closure in Drosophila and wound healing } \\
\text { processes, as well as in tissue specific epithelia such as the the lens and intestine } \\
\text { - In the Drosophillo ovaries they regulate the patterning of anterior \& posterior follicle } \\
\text { cells with Lgl acting differentially than Dig and Scrib }\end{array}$} \\
\hline $\begin{array}{l}\text { - They regulate basal protein targe } \\
\text { asymmetry and mitotic spindle } \\
\text { - Microtubules induce Pins/Gai cor } \\
\text { through Dlg/Khc-73 interactions } \\
\text { - A linear Pins/Aurora-A/Dlg pathw } \\
\text { positioning and links plus end mi } \\
\text { Dig cortical domain }\end{array}$ & & $\begin{array}{l}\text { Tubulogenesis } \\
\text { - Dlg, Scrib and Lgl are required for } \\
\text { Drosophilo trachea development } \\
\text { - They act independent of Vermiform } \\
\text { and Crumbs for trachea development. }\end{array}$ \\
\hline $\begin{array}{l}\text { Planar Cell Polarity (PCP) } \\
\text { - Dlg and Scrib regulate PCP in several contexts } \\
\text { such as polarized membrane insertion, intestinal } \\
\text { tube formation, hair stereociliary bundles, lung, } \\
\text { heart and kidney morphogenesis, and neural } \\
\text { tube closure } \\
\text { - Dig and Scrib bind core PCP components such as } \\
\text { Frizzled receptors and the transmembrane } \\
\text { Strabismus-VanGogh protein whereas Lgl binds } \\
\text { Dishevelled } \\
\text { - Scrib genetically interacts with Fat1, linking PCP } \\
\text { to the Hippo pathway }\end{array}$ & $\begin{array}{l}\text { Immunological-TCR synapses } \\
\text { - Dig1 binds Ezrin and together regulate } \\
\text { microtubule positing at the synapse periphery } \\
\text { - Dlg1 binds p } 38 \text { to drive signaling downstream } \\
\text { of TCR towards the NFAT branch }\end{array}$ & $\begin{array}{l}\text { - Dlg regulates SSR formation } \\
\text { - Olg regulates Fasll \& Shaker } \\
\text { Iocalization } \\
\text { - Dlg is negatively regulated by CaMKII } \\
\text { and Par1 } \\
\text { - OIg binds Gtaxin (t-SNARE) } \\
\text { - Dig binds and localizes Scrib } \\
\text { - Scrib negatively regulates DIg in } \\
\text { - NMIs } \\
\text { - The DlgS97-Metro-DLin7 tripartite is } \\
\text { an important perisynaptic scaffolding } \\
\text { complex }\end{array}$ \\
\hline
\end{tabular}

Fig. 1. Overview of the multitasking role of Dlg, Scrib and Lgl in different cellular and tissue contexts.

Dlg is also involved in T-cell receptor (TCR) signaling (Round et al. 2007), as Dlg1 downregulation blocks TCR-induced activation of p38 and the transcription factor NFAT, but not the alternative protein kinase JNK or the NF- $\kappa B$ transcription factor. Dlg1 directly binds p38, to drive signaling downstream of TCR towards the NFAT branch of the cascade and it has been shown to act as an orchestrator of TCR specificity (Round et al. 2007). Rho signaling plays an important role in TJ function and several studies of dominant active and negative mutants of $r h o A, R a c$ and $c d c 42$ revealed that they all disrupt the barrier function of TJs, with the most intense effect obtained with dominant active rhoA mutants (GonzalezMariscal, Tapia and Chamorro 2008). The RhoA/ROCK signaling pathway participates both in the assembly and disassembly of TJs. Moreover PKN1, a Rho effector protein, participates in the regulation of $\mathrm{TJ}$ sealing in the mammary gland by interfering with glycocorticoid signaling, consistent with observations that Rho activation perturbates TJ function in various experimental systems (Fischer et al. 2007). Furthermore, Net1 (neuroepithelioma 
transforming gene), a RhoGEF specific for the RhoA subfamily of small G proteins, interacts with the PDZ domains of Dlg1 and relocalizes Dlg1 to the nucleus whereas the oncogenic mutant of Net1 sequesters Dlg1 in the cytosol (Garcia-Mata et al. 2007). In particular, Net1 binding to Dlg1 in MCF7 breast cells, which is regulated by E-cad-mediated cell-cell interaction, enhances Net stability and increases Net1 ability to stimulate RhoA activation in these cells (Carr et al. 2009).

\subsection{Dlg, Scrib and Lgl in planar cell polarity}

The planar cell polarity (PCP) pathway, incorporating the non-canonical Wnt pathway, is best known for directing polarization of cells orthogonal to the apical-basal polarity axis within the plane of an epithelium. Apart from regulating the patterning of external epidermal structures such as wing hair cells in Drosophila and ciliary orientation, PCP controls embryonic convergent extension (CE), polarized cell division, cell direction and movement (Yates et al. 2010a). $d l g$, scrib and lgl are essential for planar cell polarity (PCP), by establishing a cross-talk between apical-basal and planar cell polarity. Dlg and Scrib have been shown to bind components of the core PCP machinery, including Frizzled receptors and the membrane protein Strabismus/Van Gogh (Stbm/Vang) (Montcouquiol et al. 2006, Kallay et al. 2006, Lee et al. 2003, Hering and Sheng 2002). The direct interaction of Dlg4 with receptors of the Wnt signaling pathway, Frizzled 1-7, link mammalian Dlg to the Frizzled signaling (Humbert et al. 2003, Hering and Sheng 2002). Dlg1 is also required for smooth muscle orientation in the mouse ureter (Mahoney et al. 2006). In addition, Dlg binds through its PDZ1 and PDZ2 domains to Stbm/Vang in order to recruit membraneassociated proteins and lipids from internal membranes to sites of new plasma membrane formation (Lee et al. 2003). In C. elegans, the unique PCP protein Vang-1 interacts with the PDZ2 domain of Dlg for its proper localization, which is required for intestinal tube formation, since in vang-1 mutant embryos the epithelial cells of the intestine are not correctly arranged along the anterior-posterior axis (Hoffmann et al. 2010). Moreover, the Pins/Dlg complex is required to establish PCP during asymmetric cell division in the sensory organ precursor cell of the notum (Bellaiche et al. 2001).

Interestingly, the mouse scrib gene genetically interacts with the vangl2 gene, a mammalian homologue of the Drosophila stbm/vang gene, involved in PCP (Montcouquiol et al. 2003). Analysis of PCP in hair cell stereociliary bundles within the cochlea in mammals, showed that Scrib is a prerequisite for the proper localization and function of PCP proteins among which is also Vangl2 (Montcouquiol et al. 2003). Further studies revealed that both mammalian and Drosophila Scrib physically interact with Vangl2 (Kallay et al. 2006) and Stbm/Vang (Courbard et al. 2009) respectively, through their PDZ domains to regulate normal development in Drosophila wing imaginal discs (Courbard et al. 2009), heart tube and cardiomyocyte organization (Phillips et al. 2007), and neural tube closure (Wen et al. 2010, Wansleeben et al. 2011). Scrib is also implicated in PCP-mediated neural tube closure through binding to $\mathrm{Cdx}$, a homeodomain transcription factor which regulates transcription of the Ptk7 PCP gene (Savory et al. 2011). A PCP-mediated requirement of Scrib has also been demonstrated for lung development (Wansleeben et al. 2011) and branching morphogenesis (Yates et al. 2010b), for kidney-branching morphogenesis and glomerular maturation (Yates et al. 2010a), and for the tangential migration of facial branchiomotor (FBM) neurons (Walsh et al. 2011). All these later studies provide insights on a very interesting and yet poorly understood role of Scrib on PCP-mediated organogenesis and the interplay of apicobasal and PCP pathways. 
Spatial organization of cells and their appendages is controlled through the PCP by a signaling cascade initiated by the protocadherin Fat in Drosophila. Fat acts through two distinct branches: the Fat polarity pathway and the Fat tumor suppressor/Hippo pathway. Vertebrates express four Fat molecules, Fat1-4. Indeed, Scrib provided the link between the Fat and the Hippo signaling cascade in vertebrates. Fat1 depletion causes abnormal cyst formation in the zebrafish pronephros, a phenotype underlying a strong genetic and direct interaction between Fat1 and Scrib. The observation that depletion of Yes-associated protein 1, a transcriptional co-activator inhibited by the Hippo pathway, ameliorated the changes caused by fat1 and scrib knockdown, shows that in the absence of Scrib and Fat1, it is the deregulation of the Hippo pathway which contributes to the formation of abnormal pronephric cysts (Skouloudaki et al. 2009).

As already mentioned, the non-canonical Wnt/Wg pathway plays a central role in PCP. A key switch at its branch point appears to be the Dishevelled (Dsh) protein, which is required for both PCP and the canonical Arm/ $\beta$-Catenin pathway (Wodarz and Gonzalez). Interestingly, a physical and functional interaction has been reported between Lgl and the signaling protein Dishevelled (Dsh) (Dollar et al. 2005). Asymmetric localization of Dsh leads to spatially defined areas of Lgl upregulation, which allows directional tissue morphogenesis and PCP organization of epithelial sheets in Drosophila embryos (Kaplan and Tolwinski 2010). In humans, Lg12 plays a critical role in branching morphogenesis during placental development. Lg12 regulates cell polarization and polarized-cell invasion guiding trophoblast invasion, yet a connection to the PCP pathway is not established so far (Sripathy, Lee and Vasioukhin 2011).

\subsection{Orientation of cell division, spindle, microtubule and centrosome positioning}

Orientation of cell division is important in establishing and maintaining normal development and tissue homeostasis from bacteria to mammals. A correct cell division plane is critical during asymmetric cell division, spindle orientation, microtubule and centrosome positioning. Several studies point out the key roles of Dlg, Scrib and Lgl in multiple aspects of cell division orientation.

One of the most well studied systems is the asymmetric division of the Drosophila neural stem cells, the so-called embryonic neuroblasts. These studies indicate that $d l g$, scrib and lgl have a function in the correct placement of cell-fate determinants, in dividing neuroblasts. Dysregulation of the mechanisms, which control the neuroblast asymmetric division, results in compromised inheritance of cell-fate determinants, triggers neoplastic transformation and promotes brain tumors (Merz et al. 1990, Caussinus and Gonzalez 2005, Betschinger, Mechtler and Knoblich 2006, Lee et al. 2006). Neuroblast division gives rise to a larger daughter cell that remains a neuroblast and a smaller daughter cell that becomes a ganglion mother cell (GMC). This process involves the segregation of the basally localized cell-fate determinants Numb, Prospero (Pros) and Brain tumor (Brat) proteins and their adaptor proteins Partner of Numb (Pon) and Miranda (Mira), into the basal GMC. This segregation is controlled by apically localized components including the Par-complex (Baz/Par3, Par6 and aPKC), as well as the Inscutable (Insc) and Partner of Inscutable (Pins) proteins. Dlg, Scrib and Lgl proteins display a cortical localization, with apical enrichment during early mitosis. Insc and Insc-dependent proteins (Insc/Par pathway) are required for the maintenance and apical enrichment of Dlg and Scrib 
proteins whereas Dlg controls the cortical recruitment of both Scrib and Lgl. In $\mathrm{dlg}$, scrib and $\operatorname{lgl}$ mutants the localization of the apical proteins is normal but the basal protein targeting is defective, resulting in a reduced apical cortical domain and a smaller size of the apical spindle. Therefore, Dlg, Scrib and Lgl are important in regulating cortical polarity, cell size asymmetry and mitotic spindle asymmetry in Drosophila neuroblasts (Albertson and Doe 2003).

The fact that apical Dlg, Scrib and Lgl may promote apical spindle pole growth is consistent with the observation that vertebrate Dlg orthologues physically interact with known microtubule-binding proteins (Albertson and Doe 2003, Brenman et al. 1998, Niethammer et al. 1998, Matsumine et al. 1996, Hanada et al. 2000). In Drosophila, kinesin Khc-73 and Dlg induce cortical polarization of Pins/Gai, acting in parallel to the Insc/Par pathway. Interestingly, Khc-73 localizes to astral microtubule plus ends and the Dlg/Khc-73 and $\mathrm{Dlg} /$ Pins protein complexes have been found to co-immunoprecipitate, suggesting that microtubules induce Pins/Gai cortical polarity through Dlg/Khc-73 interactions (Siegrist and Doe 2005, Ahringer 2005). The recent identification of an evolutionary conserved PinsLINKER domain uncovered a linear PinsLINKER/Aurora-A/Dlg spindle orientation pathway, which links the plus ends of astral microtubules to the Dlg cortical domain (Johnston et al. 2009).

Additionally, Dlg1 is important for centrosome positioning in the astrocytes. During wound-induced cell migration Cdc42 acts through Dlg1, in order to regulate the interaction of dynein with microtubules of the cell front (Manneville, Jehanno and Etienne-Manneville 2010). Dlg1 interacts with dynein via the scaffolding protein GKAP and all three proteins together control microtubule dynamics and organization near the cell cortex and at the microtubule-organizing center (MTOC), ultimately leading to centrosome positioning. Moreover, Dlg1 colocalizes with APC at microtubule plus-ends to promote microtubule polarization and centrosome reorientation (Etienne-Manneville et al. 2005, EtienneManneville and Hall 2003). However, the Dlg1-mediated recruitment of dynein is independent of its interaction with APC (Manneville et al. 2010). A crucial function of Dlg1 on microtubules has also been established for immunological synapses (Lasserre et al. 2010, Lasserre and Alcover 2010). Dlg1 and the cell cortex membrane-microfilament linker Ezrin are key players for synapse stability and symmetry. Ezrin silencing alters cell spreading and microtubule network organization at the immune synapse and leads to enhanced T-cell receptor (TCR) signaling (Lasserre et al. 2010). Ezrin-Dlg1 interaction keeps the microtubule architecture at the synapse, which in turn drives signaling microcluster dynamics and downregulation of the TCR receptor signaling. Similar to the role of Dlg1 in MTOC positioning during astrocyte migration (Etienne-Manneville et al. 2005), Ezrin and Dlg1 are necessary for a similar positioning of microtubules at the periphery of the immunological synapse (Lasserre et al. 2010).

Finally, Scrib is required for oriented cell division in the neural keel to promote morphogenesis of the neural tube epithelium (Zigman et al. 2011). Analysis of scrib mutants revealed a role of Scrib in controlling clustering of $\alpha$-catenin foci in dividing progenitors that correspond to the future subapical junctional complexes of the mature epithelium. This function of Scrib, which is independent of the canonical apicobasal polarity and PCP pathways, stresses the importance of single-cell orientation for tissue-level morphogenesis (Zigman et al. 2011). 


\subsection{Trafficking, exocytosis and polarized membrane insertion}

Exocytosis is an important membrane traffic event that mediates the transport of secreted and transmembrane proteins, as well as lipids to the cell surface (Hsu et al. 2004). This transport is highly polarized and tightly regulated, so that the molecular identity of the apical and basolateral membrane domains is maintained. It has already been proposed that the junctions in mammalian epithelial cells promote the correct spatial organization of cellular components by acting as sorting sites for a subset of vesicles (Humbert et al. 2008). The mechanisms that specify vesicle docking and fusion of intracellular membranes rely on the SNARE proteins, with t-SNAREs localized in a polarized distribution on the target membranes and v-SNAREs on the vesicles. When a v-SNARE encounters its cognate $t$ SNARE they assemble into a tight complex, which brings together the apposed membranes sufficiently close to each other for fusion to occur. As an example, Drosophila embryos with mutated Syntaxin 1 (Syn1), a t-SNARE protein uniformly distributed on target membranes, fail to cellularize (Burgess, Deitcher and Schwarz 1997). The spatial specificity of vesicle trafficking also relies on the tethering of exocytic vesicles, at defined membrane sites, by the eight-subunit exocyst (or Sec6/7) complex. Recent work has shown that the Exo84 component of the exocyst complex is required for membrane trafficking from the recycling endosome to the cell surface and the apical localization of the transmembrane protein Crumbs, whereas the mutant phenotype is suppressed by down-regulation of the Dlg and Lgl proteins (Blankenship, Fuller and Zallen 2007). Interestingly, in yeast the Lgl homologous proteins Sro7p and Sro77p directly interact with Exo84p and the t-SNARE protein Sec9p (Zhang et al. 2005), whereas the mammalian Lgl binds Syntaxin-4, a t-SNARE protein that mediates vesicle fusion, in order to direct protein trafficking (Musch et al. 2002). As the exocyst decides not only what fuses with the plasma membrane but also the site of fusion, we can conclude that Lgl family proteins affect asymmetric protein localization by targeted vesicle fusion (Wirtz-Peitz and Knoblich 2006). Furthermore, type V myosin 2 (Myo2) physically binds Sro7 and negatively regulates Sro7 function in vesicle clustering (Rossi and Brennwald 2011). Myo2 serves in a dual function: to recruit Sro7 to secretory vesicles and to inhibit its Rab-dependent tethering activity until vesicles reach the plasma membrane. Taken together, Sro7 appears to coordinate the spatial and temporal nature of both Rab-dependent tethering and SNARE-dependent membrane fusion of exocytic vesicles with the plasma membrane (Rossi and Brennwald 2011).

Furthermore, Scrib has been shown to have an important role in regulating exocytosis in neuroendocrine cells through its association with the $\beta$-Pix-GIT1 complex (Audebert et al. 2004, Humbert et al. 2008). Scrib acts as a membrane anchor for $\beta$-Pix, a guanine exchange factor (GEF), which activates Rac1 and recruits it to a functional complex regulating exocytosis of $\mathrm{Ca}^{++}$-regulated hormone release (Momboisse et al. 2009). Since small RhoGTPases have emerged as key players in membrane trafficking and Rac isoforms have been involved in various processes of exocytosis, this recent work uncovers the actual function of Scrib, $\beta$-Pix and Rac1 in exocytosis, in addition to their well-established role in cancer (Momboisse et al. 2009).

While polarized exocytosis of proteins is one of the most studied mechanisms responsible for the maintainance of cell polarity, polarized transport of specific mRNAs represents an alternative pathway (Vasioukhin 2006). It has been demonstrated that Lgl genetically interacts and is present in a complex with the fragile $X$ syndrome protein FMRP, which is responsible for mRNA transport (Zarnescu et al. 2005). This interesting finding suggests that Lgl may be involved in polarity by regulating the localization of specific mRNAs. 
Dlg plays an important role in polarized membrane insertion during cellularization. It is known that polarized membrane growth relies on the guiding cues of junctional and perijunctional proteins (Lecuit and Wieschaus 2002). The Drosophila cellularizing blastoderm provides an excellent system for studying the genetic analysis of how polarity is established, reinforced and maintained in vivo. During cellularization, an epithelium is formed de novo by growth and invagination of plasma membrane between the cortical nuclei, leading to a 20-30 fold increase of membrane surface and formation of the first columnar epithelial cells $(\sim 30 \mu \mathrm{m})$ (Mazumdar and Mazumdar 2002). This process requires the remobilization of the intracellular membrane reservoir from the endoplasmic reticulum (ER) and Golgi. Membrane trafficking is regulated in a way that allows polarized membrane delivery, with the secretory pathway and the membrane-recycling pathway guiding the membrane deposition (Dudu, Pantazis and Gonzalez-Gaitan 2004, Strickland and Burgess 2004). In the secretory pathway, membrane proteins are recruited from post-Golgi vesicles to the lateral domain of growing membranes by the Strabismus/Van Gogh (Stbm/Vang)-Dlg complex. Dlg localizes to the plasma membrane along the newly formed invaginating membrane, whereas Stbm/Vang is localized initially to the Golgi. Both Stbm/Vang and Dlg are required for membrane deposition during cellularization and their simultaneous overexpression induces expansion of the lateral membrane (Lee et al. 2003). In the membrane-recycling pathway, the apical membrane is internalized through a Dynamindependent process, travels through the Rab5 early endosome and Rab11 recycling endosome acting together with Nuf, and finally becomes exocytosed at the lateral membrane (Dudu et al. 2004, Strickland and Burgess 2004, Pelissier, Chauvin and Lecuit 2003, Riggs et al. 2003, Lecuit 2004).

\subsection{Critical functions in neuromuscular junctions and synapses}

One of the most broadly used systems to study Dlg and Scrib function has been the neuromuscular junctions (NMJs). Dlg was shown to be present in glutamatergic larval NMJs. Glutamate receptors (GluR) in Drosophila NMJs are of two different types, comprised of either GluIIA (A-type) or GluIIB (B-type) subunits, as well as the common subunits GluIIC, GluIID and GluIIE (Collins and DiAntonio 2007). Dlg controls the subunit composition of the receptor by selectively stabilizing B-type receptors at the synapse, whereas Coracle is required for A-type receptors (Chen and Featherstone 2005, Chen et al. 2005). Dlg is abundantly expressed through the postsynaptic membrane surrounding the presynaptic motor axon terminals. During larval development, the postsynaptic membrane increases enormously leading to a highly convoluted and multilayered postsynaptic membrane structure, the subsynaptic reticulum (SSR). Several years of research in this field have shed light on the role of the different Dlg protein domains (Thomas et al. 2000) and their binding partners (Thomas et al. 2000, Thomas et al. 1997a, Zito et al. 1997), the role of phosphorylation on Dlg regulation (Koh et al. 1999, Beumer et al. 2002, Zhang et al. 2007) and the key role of Dlg on membrane proliferation in the SSR of GluIIB-type receptors (Chen and Featherstone 2005, Roche et al. 2002). The synaptic targeting and localization of Dlg is a stepwise process controlled by different domains of the protein (Thomas et al. 2000). The localization of the postsynaptic Dlg was also investigated during synapse remodeling of larval NMJs, whereby the adult-specific synapses are generated. During synapse dismantling, postsynaptic Dlg becomes diffuse 
and then undetectable, followed by SSR vacuolization, through a mechanism different than that of GluRs elimination (Liu et al. 2010b).

Dlg is important for proper NMJ establishment as dlg- NMJs have defects in synapse structure and function, including an increase in bouton size and number of active zones presynaptically, as well as a poorly developed SSR (Chen and Featherstone 2005). Dlg regulates SSR expansion and is also required for clustering Fasciclin II (FasII) and Shaker proteins (Thomas et al. 1997a, Zito et al. 1997). Dlg-dependent localization of FasII to the Drosophila GluRIIB NMJs is negatively regulated by $\mathrm{Ca}++$ /calmodulin dependent kinase II (CaMKII) (Koh et al. 1999), with $\beta$ PS-Integrin (encoded by myospheroid in Drosophila) acting upstream of CamKII. Upon increased synapse activity, CaMKII phosphorylates Dlg, which dissociates from the synaptic protein complex, releases FasII, and allows for developmental growth in signal response (Beumer et al. 2002). However, sh and fasII mutations do not affect the SSR, meaning that Dlg plays a role in postsynaptic membrane regulation independent of its interaction to Sh and FasII (Schuster et al. 1996a, Schuster et al. 1996b). Further studies have shown that expression of a constitutively active form of CaMKII abolishes the accumulation of Dlg at synapses, while exerting no significant effect on the presynaptic area and localization of FasII (Morimoto et al. 2010). Postsynaptic targeting of Dlg is negatively regulated by PAR-1, which phosphorylates Dlg at a conserved Ser residue within the GUK domain (Zhang et al. 2007). PAR-1 and Dlg both affect pre- and post-synaptic development and function in a dose-dependent way. PAR-1 overexpression and Dlg inactivation lead both to active zone increase and SSR loss, whereas loss of PAR-1 and Dlg overexpression have the opposite effect and therefore confirm the antagonistic effect of PAR-1 on Dlg (Zhang et al. 2007). Like Dlg, Pumilio (Pum), a known transcriptional regulator of embryonic patterning and germline development, appears to have both pre- and post-synaptic effects in NMJs and is colocalized with Dlg and GluIIB-type boutons (Chen et al. 2008). Notable Pum directly regulates $d l g$ by binding to the Dlg-3'UTR, thereby antagonizing the effects of Dlg on neuronal structure and/or function also in the adult mushroom bodies, the anatomical site of memory storage (Chen et al. 2008).

The Drosophila dlg gene codes for two isoforms, the DlgA and DlgS97 collectively referred to as Dlg, which have been individually studied in NMJs. Both isoforms are present at the NMJs, but mutations that specifically abolish DlgS97 leave FasII largely unaffected (Albornoz et al. 2008). DlgS97 exerts its function at the NMJs by binding to Metro, a novel MAGUK protein, which stabilizes the complex of DlgS97 and the adaptor protein DLin-7 (Bachmann et al. 2010). In a remarkably interdependent manner, Metro and DLin-7 act downstream of DlgS97 to control NMJ expansion and proper establishment of synaptic boutons, making this tripartite an important perisynaptic scaffolding complex (Bachmann et al. 2010).

Membrane addition by vesicle fusion commonly involves SNARE proteins. Recent work has shown that Dlg binds and controls postsynaptic localization of the t-SNARE GUKinteracting syntaxin (Gtaxin). Gtaxin is required for proper SSR expansion and controls synaptic and muscle development in a dose-dependent manner (Gorczyca et al. 2007). Gtaxin's closest Homologues, Syntaxin 18 and Ufe1p, can mediate homotypic endoplasmic reticulum (ER) membrane fusion in the absence of other known SNAREs (Lewis and Pelham 1996, Patel et al. 1998, Hatsuzawa et al. 2000). The presumptive role of 
Gtaxin as part of the ER-specific vesicle fusion machinery, together with its requirement for SSR development, supports the idea that SSR bears at least some ER-like properties (Gorczyca et al. 2007).

Moreover, Dlg interacts at the synapses with Scrib, through simultaneous binding of both the Dlg-GUK domain and the Scrib-PDZ2 domain to the synaptic protein GUK-holder (Gukh) (Mathew et al. 2002). Apart from an increased number of active zones and reduced SSR, dlg- NMJs show severe mislocalizaton of synaptic Scrib. Loss of scrib in NMJs results in synaptic vesicle increase, decrease in the number of active zones and a thickened basal lamina, however Dlg localization and the SSR remain unaffected (Mathew et al. 2002). Apparently, the synaptic levels of Scrib have an opposite effect than Dlg in active zone number and Scrib negatively regulates Dlg function in NMJs, in contrast to their cooperation in epithelial cells and neuroblasts (Roche et al. 2002). This probably reflects the ability of Dlg and Scrib to exert their function through binding to different protein partners with distinct functions, according to their availability in the various tissues.

Scrib is also capable of influencing the morphology and function of synapses (Moreau et al. 2010). It is expressed in the soma and dendrites of adult hippocampal pyramidal cells, to regulate neuron maturation, with the synaptic strength and plasticity severely affected in scrib mutant mice. In the hippocampus of these mutants, the phenotype is associated with Rac1 activation and defects in actin reorganization, which ultimately affect memory consolidation. Scrib effects on brain function and the corresponding effects on enhanced learning, memory abilities and impaired social behavior, provide a step forward in the dissection of Scrib roles in the pathophysiology of behavior (Moreau et al. 2010). Dlg is also found at the lamina of the photoreceptor synapses. Immuno-electron microscopy revealed that Dlg marks the round profiles of R1-R6 ommatidia terminals and the photoreceptor membrane around the invaginating head of capitate projection organelles, which are the organelles from the surrounding glia (Hamanaka and Meinertzhagen 2010).

\subsection{Tubulogenesis and trachea development}

A less studied role of these tumor suppressor genes involves their function in tubulogenesis, which is the regulation of epithelial tube morphogenesis and size control in organs such as kidney, lungs, vascular system and the Drosophila trachea. So far, several studies pointed the significance of septate junctional proteins in trachea tube-size regulation (Paul et al. 2003, Wu and Beitel 2004) but more recent studies reveal a novel mechanistic framework for understanding epithelial tube size regulation in trachea. In the Drosophila trachea, tube dimensions are regulated by the luminal extracellular matrix (ECM). ECM organization requires the apical secretion of the protein Vermiform (Verm), which depends on the basolateral septate junctions (SJs) (Wang et al. 2006, Swanson and Beitel 2006). Scrib and Yurt (Yrt), another SJ-associated protein, cause tracheal tube expansion through a Verm-independent pathway (Laprise et al. 2010). Zygotic loss of $s c r i b, d l g$ and $l g l$ result in excessively long dorsal trunks, indicating that these genes are critical for tube size control. Zygotic loss of $l g l$ expression causes fully penetrant defects in SJ paracellular barrier function, whereas zygotic scrib and $d l g$ mutants do not have compromised transepithelial barriers. Furthermore, Lgl together with Crumbs have an 
additional role in apical constriction of tracheal cells, independent of their apicobasal polarity function in trachea epithelial cells (Letizia et al. 2011). Interestingly, Scrib and Crumbs do not display, during trachea elongation, the antagonistic functional interactions they have during apicobasal polarity establishment (Laprise et al. 2010). Therefore, it becomes obvious that the mechanism regulating trachea morphogenesis involves functional interactions between polarity proteins, which are different from those involved in epithelial apicobasal polarity.

\subsection{Lgl and salivary gland histolysis in Drosophila}

Although the architecture of the cells is defective in the neoplastic tissues, the structure of the other tissues is nearly normal, indicating that the loss of cell polarity may not necessarily be the major cause of cell transformation. Therefore, further investigations of $l g l$ mutant tissues and organs are important in order to unravel distinct mechanisms with critical roles in tumorigenesis. Along these lines the larval salivary glands constitute a particularly suitable model system for studying developmental cell fate, as the glands are essentially made of one single type of large epithelial cells, containing highly polyploidy nuclei with polytene chromosomes. The salivary glands produce and secrete glue proteins at the onset of metamorphosis and all the cells then degenerate synchronously in a rapid process resulting in a full histolysis of this tissue in about 14 hours. The lgl gene critically controls the degenerative process leading to salivary gland histolysis (Farkas and Mechler 2000 and references therein) and recent studies revealed that the $\lg l$ gene controls this degenerative process, which is induced by the steroid hormone ecdysone during metamorphosis. This process happens to be fully independent from the function of $l g l$ in cell polarity (Farkas and Mechler 2000). Previous results have shown that reduced lgl expression delays salivary gland histolysis whereas over-expression accelerates this process without affecting larval and pupal development. More recent investigations have shown that the Lgl protein in combination with nonmuscle myosin regulate in the cytoplasm access to chromatin modifiers, remodeling and transcription factors necessary for the implementation of salivary gland degeneration (Farkas et al. 2011). This process is relatively complex and involves the steroid activation of Broad-Complex (BR-C), a BTB/POZ-transcription factor and primary response component in this cascade, which leads to salivary gland histolysis and induction of a set of secondary genes. In wild type salivary glands, chromatin remodeling factors are localized in the nucleus to bind chromatin. In lgl salivary glands the BR-C Z1 factor is synthesized, but is unable to bind to chromatin, and accumulates in the cytoplasm and in the cortical nuclear zone devoid of chromatin (Farkas et al. 2011) and additionally the secondary genes remain quiescent (Ashburner 1974; Richards 1976). Through a cascade of gene expression the salivary glands undertake profound morphological changes, characterized by the secretion of cellular components into the lumen of the gland, which ultimately leads to the death of the cells upon activation of death genes and caspases. Although the mechanism by which chromatin access of remodeling and transcription factors is regulated by $l g l$ is poorly understood, the occurrence of WD40 motifs in the Lgl protein and the requirement of nonmuscle myosin heavy chain suggest that these factors may bind to $\mathrm{Lgl}$ in order to be assembled together with other components or alternatively become modified to get access to chromatin. 


\section{Dlg, Scrib and Lgl in cancer development}

\subsection{New emerging roles for vertebrate $d l g$, scrib and $I g I$}

Neoplastic growth depends on the cooperation of several mutations, ultimately leading to major rearrangements in cellular behavior. Changes in tissue homeostasis, acquisition of invasive cell characteristics and tumor formation are often linked to the loss of epithelial cell polarity. During carcinogenesis, the grade of neoplasia correlates with impaired cell polarity. $d l g$, scrib and $l g l$ encode tumor suppressor proteins and orthologs of this evolutionary conserved pathway are lost in human carcinomas with high frequency (Humbert et al. 2003, Humbert et al. 2008, Yamanaka and Ohno 2008, Reischauer et al. 2009). Although the role of these genes in mammals is still not well understood and often controversial, accumulated evidence has shed light on their oncogenic and tumorsuppressing function.

Scrib and Dlg1 are targeted for ubiquitin-mediated proteolysis by the E6 oncoprotein from high-risk strains of human papillomavirus (HPV) (Humbert et al. 2003, Gardiol et al. 1999, Nakagawa and Huibregtse 2000, Tomaic, Pim and Banks 2009), which has a causal role in the development of cervical cancer (Nakagawa et al. 2004). Furthermore, the viral human TLymphoma virus type 1 (HTLV1) Tax protein, crucial for viral replication and malignant transformation leading to T-cell leukemia, binds directly to Dlg1 resulting in hyperphosphorylation of Dlg, which promotes abnormal proliferation of cells (Grassmann, Aboud and Jeang 2005, Hall and Fujii 2005). Both Tax and high-risk HPV E6 bind to the PDZ domains of Dlg through their specific PDZ-binding motif (PBM) they contain (Hall and Fujii 2005). In addition, the PBM-containing Tax and APC compete for binding to Dlg (Hall and Fujii 2005), thereby providing insights on how viral proteins interfere with normal cell function. Similarly, the PBM domain of the NSI protein, from the highly pathogenic avian influenza A virus H5N1, contains an ESEV motif, which allows it to bind directly to Dlg, Scrib and other PDZ-containing proteins (Liu et al. 2010a). Notably, NSI proteins, with an ESEA-containing PBM domain, can enhance viral replication up to 4-fold, relocalize Scrib into cytoplasmic puncta concentrated in perinuclear regions and also protect cells from apoptosis. As this latter effect on apoptosis can be reversed by introducing scrib-siRNAi, these viruses most likely perform their function by disrupting the Scrib proapoptotic function (Liu et al. 2010a).

Several pieces of evidence show that human Dlg and Scrib are downregulated during malignant progression of colon and lobular breast cancers (Gardiol et al. 2006, Navarro et al. 2005). Both proteins colocalize in colon mucosa and changes in their expression patterns are correlated with loss of tissue architecture during carcinogenesis in the colon (Gardiol et al. 2006). Another study shows that Dlg1, Scrib and Lgl1 are widely distributed in normal ocular tissues, particularly in the retinal neurons, but upon ocular carcinogenesis these proteins are initially mislocalized in retinal layers and subsequently downregulated. The decreased levels of these proteins are related to the late invasive stage of this cancerous process (Vieira et al. 2008). In the mammary epithelia, Scrib depletion disrupts cell polarity, blocks three-dimensional morphogenesis, inhibits apoptosis and induces dysplasia in vivo (Zhan et al. 2008). In this tissue type, Scrib cooperates with c-Myc in order to induce epithelial changes and tumors, by blocking activation of the apoptotic pathway. Interestingly, spontaneous mammary tumors in mice and humans exhibit both downregulation and mislocalization of Scrib (Zhan et al. 2008). Decreased expression and 
changed localization of Scrib is also associated with histopathological differentiation and lymph node metastasis in endometrial cancer (Ouyang, Zhan and Dan 2010) whereas Scrib cytoplasmic mislocalization is also associated with T-cell leukemia (Okajima et al. 2008).

A study performed in colorectal adenomas and adenocarcinomas suggested that Scrib could also be involved in the early steps of colon carcinogenesis (Kamei et al. 2007), as overexpression and cytoplasmic distributions of Scrib were primarily identified as early events of this process. In these colon cells, Scrib accumulation was shown to overlap with the cytoplasmic accumulation of $\beta$-Catenin, suggesting that changes in the APC/ $\beta$-Catenin pathway during colon carcinogenesis could be involved in Scrib mislocalization (Kamei et al. 2007). A very recent study has shown that Scrib is universally overexpressed in cultured tumor cell lines and genetically disparate cancer patient series of tissues such as colon, liver, lung, bladder, breast, ovary, uterus, testis, prostate and CNS (Vaira et al. 2011, Namdarian et al. 2011). Likewise, normal membrane association of Scrib is altered in tumors where Scrib is mislocalized in the cytosol. In a lung adenocarcinoma model, small interfering RNA silencing of Scrib inhibited tumor cell invasion (Vaira et al. 2011). Furthermore, the small non-coding RNA microRNA 296 (miR-296), which is progressively lost during tumor progression in a number of cancers, transcriptionally represses Scrib. In turn, loss of miR296 causes aberrant increase and mislocalization of Scrib in human tumors, uncovering a new regulation of Scrib in cancer (Vaira et al. 2011). Lgl1 has also been associated with poor clinical prognosis for cancer patients. In colorectal and breast carcinoma lines, ZEB1 (a Zfh-1 family member of transcription factors) regulates the levels of Lgl2 (Reischauer et al. 2009). In zebrafish, the observation that epidermal neoplasia and epidermal-to-mesenchymal transition (EMT) in $\lg 12$ mutants is promoted by the ErbB signaling, a pathway of high significance in human carcinomas, provides another mechanistic link between neoplasia and TSGs (Reischauer et al. 2009).

\subsection{New insights into the mechanisms of cancer initiation and progression}

In the last years, a great number of very interesting publications provided us with information on new and unexpected findings on the role of scrib, lgl and $d l g$ in cancer initiation and the progressive steps leading to tumorigenesis. In particular, these TSGs helped us to understand the role of cell competition and of the tumor microenvironment in tumor survival and progression, as well as the role of JNK-mediated apoptosis in this system. To date, research on scrib, $l g l$ and $d l g$ has focused on their similar effects and phenotypes, the interdependent localization in various tissues and the cooperation of the three genes in establishing polarity. Nowadays, it becomes obvious that they play a broader role than initially thought, through the cooperation with individual partners and signaling pathways, in a tissue and cell-type specific context. The cellular context and the neighbouring cells of the surrounding tumour environment are recognized as important regulators in cancer progression (Brumby and Richardson 2005, Humbert et al. 2008, Mohamet, Hawkins and Ward 2011, Pagliarini and Xu 2003, Schmeichel 2004, Woodhouse and Liotta 2004). Along these lines, the analysis of cancer-disposing mutations in only a subset of cells or in clones within the context of a wild type surrounding is gaining more interest, compared to the analysis of the multi-step nature of tumor progression in the context of a whole organism, since it offers a reasonable approximation to the clonal nature of human cancers. 
Analysis of scrib- mutant clones in the Drosophila eye imaginal discs has shown that tumor development is suppressed by the JNK-mediated apoptotic pathway activated by the surrounding wild-type cells, whereas the neoplastic and metastatic potential is regained through the synergistic effect of a simultaneous up-regulation of Ras signalling within the same clones (Pagliarini and Xu 2003, Brumby and Richardson 2003, Leong et al. 2009). These results underline the effect of the surrounding normal cells on the transformed scrib- clonal cells, which leads to a cell competition similar to the one observed in the mammalian cancers (Etienne-Manneville 2009, Tapon 2003, Kango-Singh and Halder 2004, Vidal et al. 2010, Leong et al. 2009, Wu, Pastor-Pareja and Xu 2010) (Figure 2). In a model for Scrib tumorigenesis, analysis of the downstream pathways in scrib- epithelial clones revealed that the polarity defects are mediated by $\mathrm{aPKC}$, independent of Crumbs, whereas an excessive cell proliferation is restrained by JNK-mediated apoptosis. Upon simultaneous activation of either Ras or Notch, JNK-mediated apoptosis is blocked, and Ras/Notch together with JNK cooperatively promote tumor growth and invasion (Leong et al. 2009). In other words, while JNK activation promotes the death of scrib- clones, JNK drives tumor progression in the context of Ras ${ }^{v 12}$ Scrib- $^{-}$clones (Vidal 2010). Another report provided a molecular link between loss of polarity and tumorigenesis, since scrib-, dlg- and lgl- clonal cells in a wild type surrounding become metastatic only in combination with Ras $^{v 12}$ activation, resulting in JNK activation and E-cad inactivation (Igaki, Pagliarini and $\mathrm{Xu}$ 2006). A study in malpighian tubules proceded a step further, showing that indeed Ras functions downstream of Scrib to regulate the transformation of normal stem cells to cancer stem cells, and that several signal transdunction pathways (including MAPK, RhoA, PKA and TOR) mediate the function of Ras to promote this stem cell transformation (Zeng et al. 2010). Competition between clonal tissues and wild type surrounding can involve several players, since in Ras ${ }^{v 12}$ scrib $^{-}$epithelial clones overexpression of $s d s 22$, a new tumor suppressor gene in Drosophila, can prevent tumor formation and metastasis by inhibiting myosin II and JNK activity (Jiang et al. 2011). A genome-wide screen for genes cooperating with Ras (Brumby et al. 2011), confirmed the competitive advantage of Rac1, RhoGEF2 and pbl together with Ras in the clonal system, which leads to JNK upregulation. Remarkably, this JNK activation was sufficient to confer invasive growth in the clonal setting but not in the whole-tissue system. The fact that JNK-mediated tumorigenesis, in cooperation with Ras in the clonal system, resembled the situation in mammalian breast epithelial cells shows that the knowledge gained from clonal analysis in Drosophila can help us elucidate tumorigenesis in the mammalian system. Interesting is also that, Rho1 and Rac are critical for the cooperation of Dlg with Ras in the whole-tissue context (Brumby et al. 2011). Along the same line, when lgl is mutated in a mosaic tissue, the lgl- clonal cells become the "losers" in cell competition. However, simultaneous overexpression of the Ras signalling pathway or of the yorkie (yki; a transcription factor, which is suppressed by the Salvator/Warts/Hippo pathway) in lglclones, causes overgrowths and JNK-mediated apoptosis at the periphery of the transformed clones (Grzeschik et al. 2010a, Grzeschik, Parsons and Richardson 2010b, Tamori et al. 2010, Mair 2010, Alderton 2010, Menendez et al. 2010). Moreover, JNKmediated elimination of $l g l-$ clonal cells was relieved and the overgrowth potential was reestablished by upregulation of c-Myc, proving that $\mathrm{lgl}-$ clonal death is driven mainly by cMyc-induced cell competition (Froldi et al. 2010). Simultaneous downregulation of the $l g l$ and the JNK pathway in the whole-tissue system results in phenotype reversion of tumor 
growth, absence of the giant larvae and recurrence of pupariation, thereby showing that JNK activity is essential for overgrowth and invasion of $l g l$ tumorous discs (Zhu et al. 2010). Among the wide palette of cellular events leading to JNK activation is the dTNF (tumor necrosis factor)/Eiger. Eiger is the sole Drosophila member of the TNF superfamily and its dysregulated expression in imaginal disc cells results in JNK-mediated apoptosis (Vidal 2010, Cordero et al. 2010). The role of mammalian TNF in both pro-tumor and anti-tumor function are well documented and recent work suggests that both aspects of TNF function are also conserved in Drosophila. On one hand, JNK-dependent cell death in scrib and $d l g$ clones requires dTNF, consistent with its role as a "tumor death factor" (Igaki 2009). On the other hand, in tumors deficient for scrib and $d l g$ that also express Ras, the TNF signal is converted into a signal which promotes tumor growth and invasion, in accordance with the "tumor promoting" function of mammalian TNF (Cordero et al. 2010). More precisely, upon dTNF downregulation, cell death in dlg and scrib clones is blocked and in situ outgrowths appear, probably by TNF-mediated extra-cellular matrix (ECM) remodelling (Vidal 2010, Cordero et al. 2010). However, a similar effect on clone survival by dTNF knockdown in $l g l$ clones was not observed, meaning that there are gene-specificities among the three TSGs

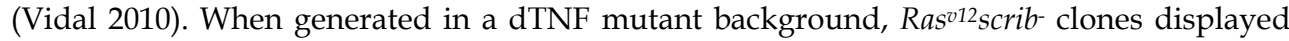
non-invasive in situ overgrowth. Similarly, in whole Ras ${ }^{v 12}$ scrib-dTNF- animals, development proceeded up to pupal stages, overcoming the "giant larvae" phenotype (Figure 2) (Vidal 2010, Cordero et al. 2010). These recent results suggest that several of the critical overgrowth phenotypes of scrib, dlg and $\operatorname{lgl}$ in the clonal and whole-tissue context are mediated by dTNF and that dTNF pro-tumor function depends partially on JNK activation in tumor cells, which provides a switch from in situ to invasive growth. Immunostaining experiments that detected dTNF in a punctuated, intracellular vesicle pattern at the periphery of hemocytes associated with the $d l g$-group clones, indicate that dTNF expression in hemocytes is sufficient for dTNF/JNK pathway activation within dlg-group clones, and mark the importance of hemolymph and non-cell autonomous immune response in tumor progression (Vidal 2010, Cordero et al. 2010).

So far, the mechanism by which the surrounding normal tissue exerts antitumor effects against $d l g$, scrib or $\mathrm{lgl}$ clones remained elucive. New results from clonal analysis in Drosophila imaginal discs have shown that JNK activation from the wild type surrounding leads to upregulation of PVR, the Drosophila PDGF/VEGF receptor, which subsequently activates the ELMO/Mbc phagocytic pathway, and which in turn eliminates the oncogenic clonal cells by engulfment (Ohsawa et al. 2011). From an evolutionary point of view, the development of such mechanism, which senses and eliminates "neoplastic" tumorsuppressor mutant cells such as those of scrib- and $\mathrm{dlg}^{-}$but not "hyperplastic" ones (in which despite of overproliferation, cells are normally shaped and retain a differentiated epithelial monolayer, such as those of the Hippo pathway and PTEN) (Ohsawa et al. 2011), shows the necessity to specifically eliminate the high-risk malignant neoplastic cells before they confer any harm to the organism. The recent results concerning the function of these TSGs are of great importance as they: (1) promote the basic understanding on cancer development in a tissue and cell-type specific context, (2) recapitulate the situation of cancer development and metastasis in humans, and (3) recognize the advantage of Drosophila as a model system of choice in order to elucidate the role of these proteins at a mechanistic level and the molecular wiring that swifts the balance from normal to transformed cells in an otherwise wild type organism. 


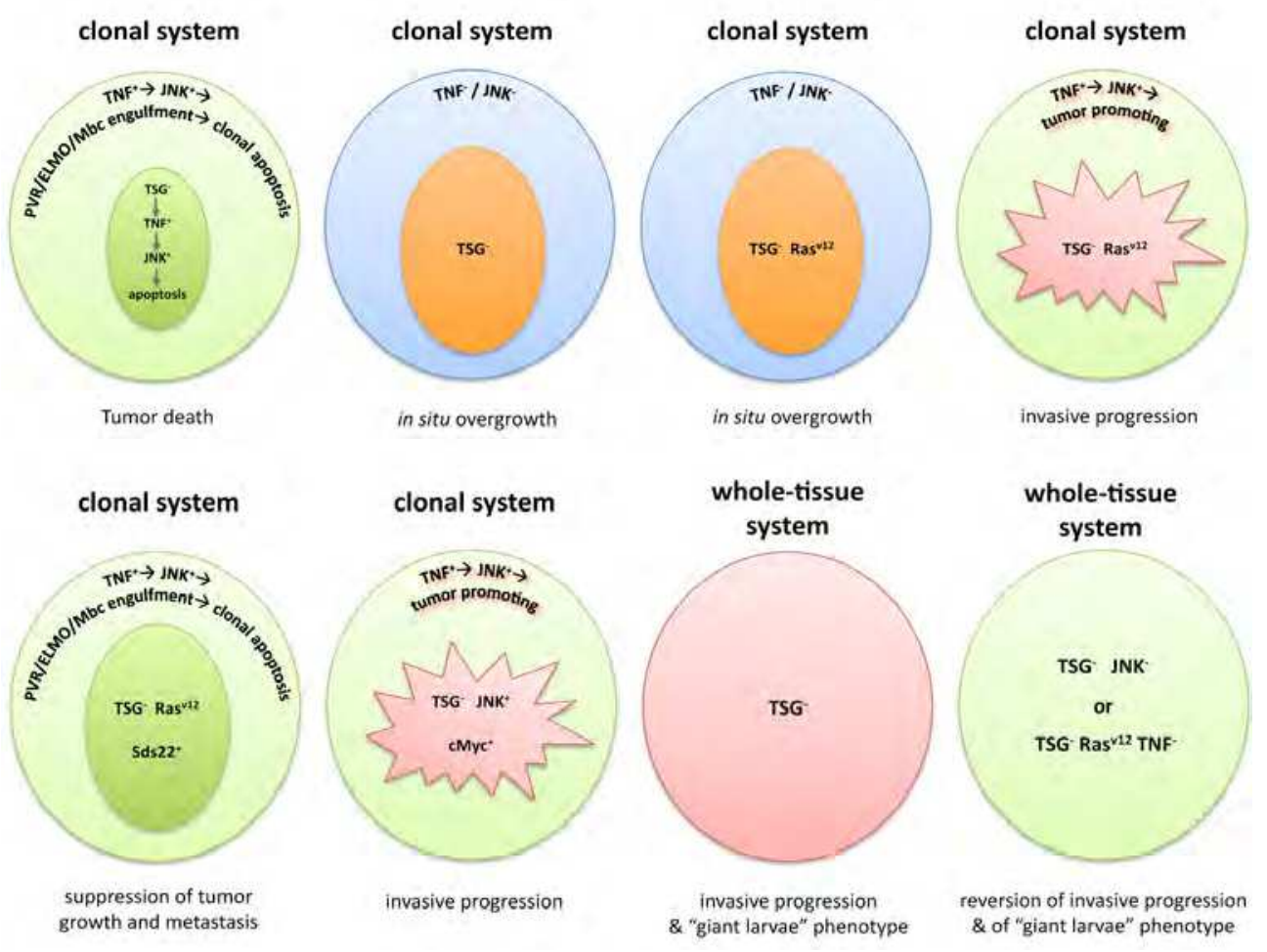

Fig. 2. Simplified model showing the most important genetic interactions of scrib, dlg and lgl TSGs with the TNF, JNK and Ras signalling pathways at the clonal and the whole-tissue system (for a more detailed analysis and the gene-specific interactions of the individual TSGs refer to the text).

\section{DIg, Scrib and Lgl in the Drosophila testis}

So far, the role of Dlg, Scrib and Lgl in testis development has been underestimated, as mutations in these genes do not result in tumors. On the other hand, testes do not possess an epithelium similar to the ovarian follicular epithelium, which facilitates the analysis of apicobasal polarity. The more intensive investigation of the Drosophila testis in the last 15 years has shed light on basic mechanisms, signaling molecules and cytoskeletal proteins involved in the progressive development of male gonads to adult testis, which provided markers and tools required for subsequent analysis. In the Drosophila testis, the somatic cells of the hub form the organizing center that recruits the germline stem cells (GSCs), creating the male stem cell niche (Fuller and Spradling 2007, Lin 2002). Upon asymmetric stem cell division, each GSC produces a new GSC attached to the hub and a distally located gonialblast, whereas each somatic stem cell (SSC) pair divides to generate two SSCs and two 
somatic cyst cells (SCCs) (Figure 3). The gonialblast divides mitotically four times in 16 interconnected spermatogonial cells surrounded by the two SCCs (Yamashita et al. 2007, Fuller and Spradling 2007, Wong, Jin and Xie 2005). The spermatogonial cells differentiate to primary spermatocytes, which enter the pre-meiotic phase (Fuller 1993). The physical contacts among the testis cell populations are critical as they allow the exchange of signals among GSCs and SSCs as well as SCCs, spermatogonial cells and spermatocytes that promote tissue survival and testis homeostasis.

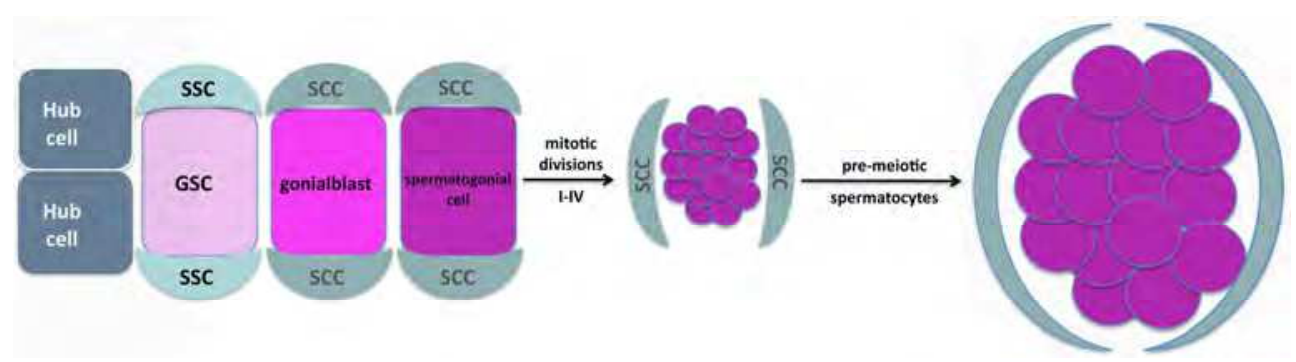

Fig. 3. Diagram depicting early spermatogenesis in Drosophila. Abbreviations: GSCs, germline stem cells; SCCs, somatic cyst cells; SSCs, somatic stem cells.

We have recently investigated a new role of $d l g$ in the Drosophila testis (Papagiannouli and Mechler 2009, Papagiannouli and Mechler 2010). In contrast to the overgrowth phenotypes observed in imaginal discs and brain hemispheres, $d l g$ inactivation leads to testis degeneration during early larval development. The $d l g$ testes are extremely small, with reduced number of GSCs loosely attached to the hub (Figure 5B, F). The Dlg protein is present in all somatic cells including the hub, SSCs and SCCs (Figure 4A-D) and the specific requirement of $d l g$ in these cells is further supported by the finding that the mutant phenotype is rescued by expressing dlg in somatic cells but not in germ cells (Papagiannouli and Mechler 2009). In SSCs and early SCCs $d l g$ plays a critical role in the establishment of a normal cyst structure, whereas in spermatogonial and spermatocyte stages $d l g$ is critical for cyst survival, growth, expansion and maintenance of the integrity of the cysts' microenvironment. Presumably, $d l g$ is required for establishing and maintaining a tight connection between GSCs and SSCs around the hub. The connection between gonialblasts and SCC is also maintained during the mitotic divisions. In SSCs and early SCCs, dlg acts critically to establish a normal cyst structure, whereas in further spermatogonial and spermatocyte stages $d l g$ is significant to the survival, growth and expansion of the cyst (Papagiannouli and Mechler 2010).

A very interesting finding was the formation of wavy and ruffled plasma membrane in $d l g$ over-expressing cells capping the spermatocyte cysts. Up to now, there is no mechanism describing how SCCs in Drosophila testis grow enormously, elongate and ensheath the germ cells of spermatogonial and spermatocyte cysts or how spermatid differentiation and individualization is guided by the polarized head and tail SCC. One way to interpret this result would be to consider that Dlg regulates the intensity of germ cell encapsulation through the Egfr pathway, which is the major signaling pathway active at the microenvironment of the spermatogonial cysts (Kiger, White-Cooper and Fuller 2000, Tran, 
Brenner and DiNardo 2000). Membrane ruffling, detected in somatic cells upon dlg overexpression, is highly reminiscent of the formation of lammellipodia-like structures, formed upon up-regulation of Rac1 in SCCs (Sarkar et al. 2007). Rac1 is a downstream component of the Egfr pathway and acts antagonistically to Rho in order to regulate germ cell encapsulation; moreover, Rho activation perturbates TJ function in various experimental systems (Fischer et al. 2007). It has already been shown that Dlg regulates membrane proliferation in a subset of NMJs in a dose-dependent fashion (Budnik et al. 1996) and is an important player in the process of polarized membrane insertion during cellularization (Lecuit and Wieschaus 2000, Dudu et al. 2004, Strickland and Burgess 2004, Lee et al. 2003). The fact that membrane proliferation is also involved in mechanisms such as tissue spreading and cell surface extensions, including membrane ruffles (Lecuit and Pilot 2003, Albertson, Riggs and Sullivan 2005) and combined with our results on SCCs membrane ruffling upon Dlg overexpression, could mean that polarized membrane insertion, mediated by Dlg, might conduct SCCs growth, expansion and spreading over the germ cells of testicular cysts.

Interestingly, our recent results have also shown a requirement of Scrib and Lgl for normal testis development. Scrib and Lgl are localized in the somatic hub, SSCs and SCCs. Scrib is also present in the germline including the spermatocytes and the fusome (Figure 4E-H), with its localization in fusome being dispensable (Lighthouse, Buszczak and Spradling 2008). Lgl has a marked localization at the fusome (Figure 4I-L). The germline localization of Scrib and Lgl is particularly interesting as it distinguishes them from Dlg, which is localized and is exclusively required in the somatic lineage. Examination of 6-7 days-old scrib and $l g l$ mutant testis from giant larvae, revealed a dramatic reduction in the size of scrib and $\mathrm{lgl}$ testis. scrib testes show defects in the male stem cell niche, with less GSCs, gonialblasts and reduction in the transit amplifying spermatogonial cells (Figure 5C, G). The phenotype of the $\lg l$ testes was more severe, with defects in the male stem cell niche, fewer GSCs loosely attached to the hub and few spermatogonial cysts and with progressive spermatocyte cyst disappearance leading to testis atrophy (Figure 5D, H). The extensive defects in $d l g$, scrib and lgl mutant testes, underline their importance in the establishment and maintenance of the male stem cell niche and proper testis differentiation.

Results obtained in the cancer and testis fields, regarding the role of the microenvironment and of apoptosis, point out the similarities of the basic mechanisms underlying the function of these genes. Our results from the Drosophila testis are in agreement with the newly investigated role of these genes in the cancer field. The importance of neighboring cell populations is illustrated in the case of testis where the somatic and germline cells create a microenvironment in the male stem cell niche and in the spermatogonial and spermatocyte cysts, which is required for mutual somatic and germline survival that promotes GSC maintenance and testis differentiation. The effect of Dlg, Scrib and Lgl, when signaling pathways emanating from the somatic and germ cells are affected, and the comparative analysis of apoptosis in the testis and in mosaic clones of the tumor microenvironment are some of the questions we try to investigate. Answering these questions will help us understand how the cell type-specific cellular content (cell intrinsic effects), microenvironment and signaling pathways cooperate with $d l g$, scrib and $l g l$ in the various tissues. Although $\mathrm{Dlg}$, Scrib and $\mathrm{Lgl}$ act in a slightly variable way in the various tissues and bind to different partners according to the protein availability (Roche et al. 2002), they can 
still be considered as major players in the pathways they participate in, with a conserved function in the broader sense. Using the knowledge obtained in these systems will allow us to study their function in the testis in a comparative way.
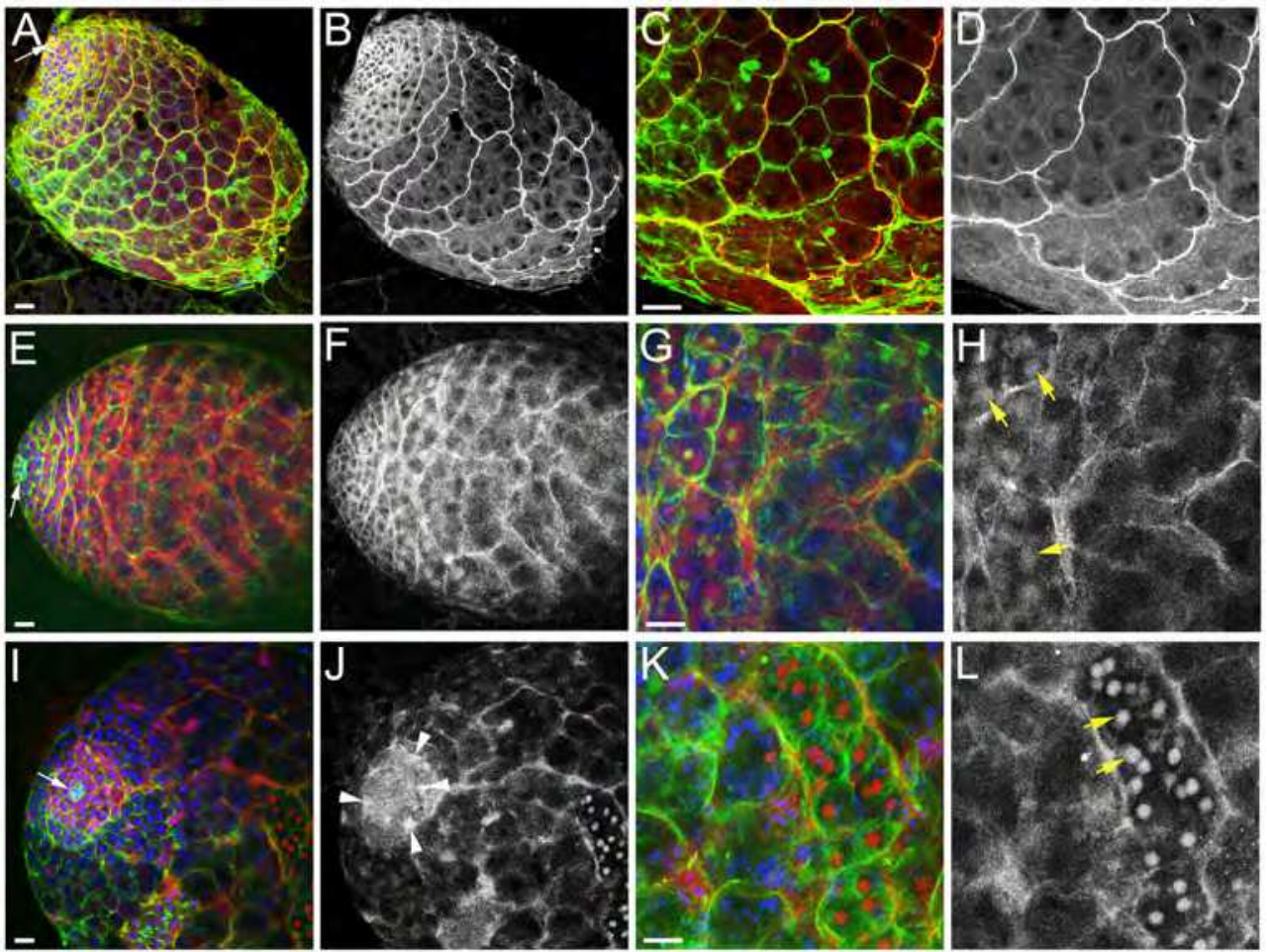

Fig. 4. Pattern of Dlg, Scrib and Lgl distribution in 3rd instar larval testis. (A-D) Wild type testis stained for F-actin with phalloidin (green), DNA with DAPI (blue) and immunostained for Dlg (red). (C) and (D) are enlargements of (A) displaying the spermatocyte cysts, (B) and (D) display only the Dlg staining, marking the hub, SSCs and SCCs. (E-H) Scrib-GFP enhancer trap line showing Scrib localization (red) and stained for F-actin with phalloidin (green) and DAPI (blue). $(\mathrm{G})$ and $(\mathrm{H})$ are enlargements of (E) displaying the spermatocyte cysts, $(\mathrm{F})$ and $(\mathrm{H})$ display only the Scrib-GFP, marking the hub, SSCs, SCCs and the spermatocytes with the fusome (yellow arrows). (I-L) Lgl-GFP enhancer trap line showing Lgl localization (red), stained for F-actin with phalloidin (green) and DAPI (blue). $(\mathrm{K})$ and $(\mathrm{L})$ are enlargements of (I) displaying the spermatocyte cysts, $(\mathrm{J})$ and $(\mathrm{H})$ display only the Lgl-GFP, marking the hub, SSCs (arrowheads in J), SCCs and the spermatocytes with the fusome (yellow arrows). Testis hub is oriented towards the left (white arrows). Bar: $15 \mu \mathrm{m}$. 

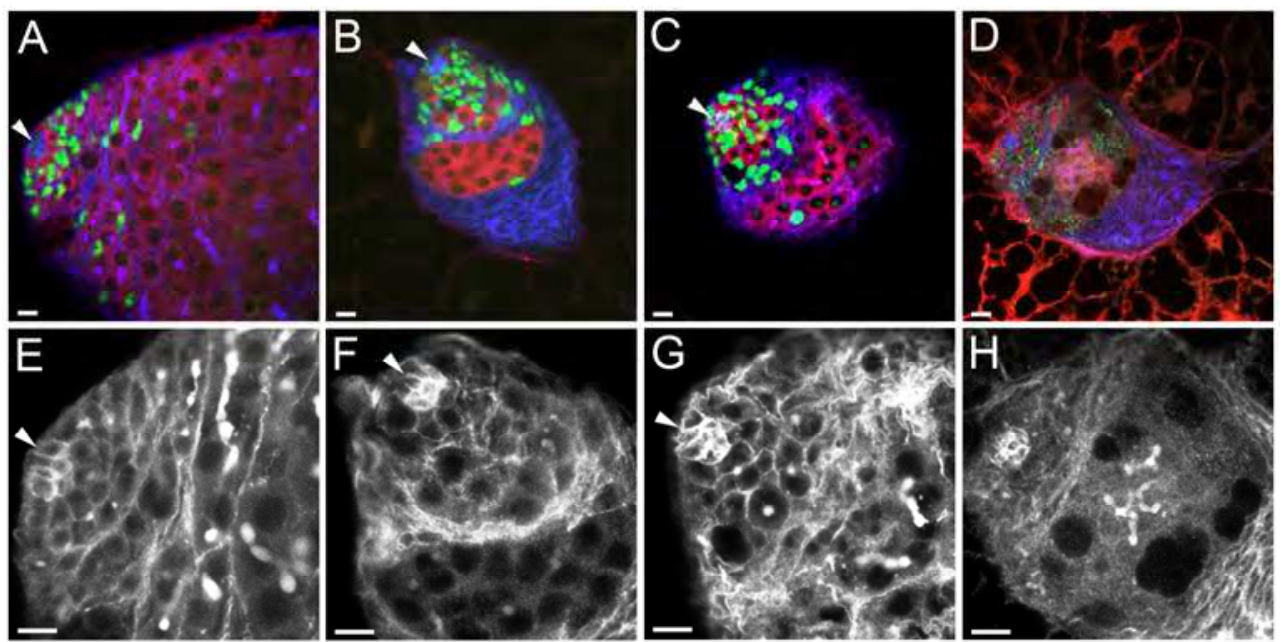

Fig. 5. Testis in wild type, $d l g$, scrib and $l g l$ 3rd instar larvae. Testes from (A, E) wt, (B, F) $d l g$, $(\mathrm{C}, \mathrm{G})$ scrib and (D, H) lgl larvae stained for Vasa (red), $\mathrm{Tj}$ (green), and Arm+a-Spectrin (blue). Low panel pictures (E-H) are enlargements of the hub region shown in (A-D), showing only the co-staining of Arm and a-Spectrin. Testis hub (arrowheads) is oriented towards the left. Bar: $15 \mu \mathrm{m}$. Staining reveals a dramatic reduction in the size of scrib and $l g l$ testis. scrib testes show defects in the male stem cell niche, with less GSCs, gonialblasts and reduction in the transit amplifying spermatogonial cells. $l g l$ testes show defects in the male stem cell niche with fewer GSCs loosely attached to the hub and few spermatogonial cysts, leading to spermatocyte cyst disappearance and testis atrophy, reminiscent of the $\mathrm{dlg}$ mutant testis (Papagiannouli \& Mechler, 2009).

\section{Conclusions}

Cancer is generally considered as a failure in the normal progression of differentiation. In recent years, developmental biology has contributed a great deal to cancer research. The reason of this success lies mainly in the recognition that cancer is a genetic disease, in which the normal pathway of cell fate and cell differentiation has been altered. The role of the tumor suppressor genes $d l g$, scrib and $l g l$ as key junctional components in cell-type and tissue specific contexts has been analyzed in this review. It becomes obvious that the cytoskeleton is not seen anymore as a fixed structure but a dynamic and adaptive structure, whose components and regulatory proteins are in constant flux. Furthermore, it organizes the content of the cell, connects the cell with the external environment and coordinates forces that enable the cell to move and change shape. Looking at the cell not as an "inert playground for a few masterminding molecules" (Weiss 1961) but as an integrated whole, "an hierarchical ordered system of mutually interdependent molecular groupings and supramolecular entities" (Weiss 1961, Fletcher and Mullins 2010) can help us understand the role of these TSGs as safeguards of normal development, tissue homeostasis and tumor prevention.

Over the last three decades Drosophila has become the organism of choice for molecular and genetic investigations in eukaryotic biology. Its emergence as an animal model system is 
closely related to the rapid advances in recombinant DNA technology and other methods established in decades of classical genetics and embryology. Given the striking degree of evolutionary conservation of genes and signaling pathways, in particular of disease-causing genes, and the general principles that govern biological processes, sometimes even to the extent that a mouse gene can functionally replace its fly homologue, what we can learn from flies is often relevant to higher organisms, including humans (Gonzalez 2007, Jaekel and Klein 2006). This surprising conservation, together with the recent advances in genetic tools, such as MARCM (Lee and Luo 2001, Wu and Luo 2006), lineage tracing (Potter et al. 2010), multi-color cell labeling (Hadjieconomou et al. 2011, Hampel et al. 2011, Cachero and Jefferis 2011), cell-type specific RNAi (Brand and Perrimon 1993) and genome-wide analysis made Drosophila a powerful model organism in elucidating basic cellular and tissue functions and in modeling cancer and other diseases. In the last years, a handful of review articles and conferences focused on the efforts and advances in modeling human diseases in Drosophila (Pfleger and Reiter 2008, Crnic and Christofori 2004, Gilbert 2008, Botas 2007, Caldeira et al. 2009, Froldi et al. 2008, Reiter et al. 2001) from cancer, metastasis and neurogenerative diseases to obesity, metabolism and congenital heart disease. All these studies have shown that analysis of human diseases in Drosophila can go further than the phenotypic results and the ability to assign a function, in elucidating the mechanisms underlying disease pathology through a straightforward experimental design, thereby providing valuable entry points for later validation in mammalian systems and humans and identify candidate therapeutic agents. The fact that cancer and tumor suppressors underlie almost all basic cellular mechanisms from polarity, cell architecture and adhesion to gene regulation and cell specification, and from trafficking and proper cell compartmentalization to microenvironment signal exchange and neighboring cell competition, prove the necessity of Drosophila as a workhorse in unraveling the mechanisms of normal development. Compared with experiments in vertebrates, the large screens facilitated in Drosophila due to the low cost, the short generation time, the capacity for experiments with large numbers of animals and the availability of large collections of loss-of-function and overexpression mutant strains together with the power of genetics, that allows researchers to manipulate the fly genome at the level of precision, made the tiny fruit fly the organism of choice in several cases (Botas 2007, Froldi et al. 2008). Finally, the use of innovative technologies such as microarrays and nanotechnology, combined with novel computation and bioinformatics, has allowed genome-wide analysis of Drosophila, comprehensive analysis of the chromatin landscape (Kharchenko et al. 2011), cis-regulatory map of the Drosophila genome and transcription co-binding relationships (Negre et al. 2011), and high-resolution of transcriptome dynamics throughout development (Graveley et al. 2011). All these studies have laid the carpet for identifying gene networks and complex gene and pathway interactions. Therefore, it becomes clear that we have still a long way to go on the enormous potential to study human genetic conditions and modeling cancer and metastasis in this simple invertebrate.

\section{Acknowledgements}

We would like to thank the Drosophila community for providing us generously with fly stocks and antibodies during the course of this work. This work was supported by DFG/SFB873 to F. Papagiannouli, and by grants GARČR P302/11/1640 to B.M. Mechler and grants MSM 0021620806 and LC535 to the Charles University in Prague. 


\section{References}

Ahringer, J. (2005) Playing ping pong with pins: cortical and microtubule-induced polarity. Cell, 123, 1184-6.

Albertson, R. \& C. Q. Doe (2003) Dlg, Scrib and Lgl regulate neuroblast cell size and mitotic spindle asymmetry. Nat Cell Biol, 5, 166-70.

Albertson, R., B. Riggs \& W. Sullivan (2005) Membrane traffic: a driving force in cytokinesis. Trends Cell Biol, 15, 92-101.

Albornoz, V., C. Mendoza-Topaz, C. Oliva, J. Tello, P. Olguin \& J. Sierralta (2008) Temporal and spatial expression of Drosophila DLGS97 during neural development. Gene Expr Patterns, 8, 443-51.

Alderton, G. K. (2010) Tumorigenesis: To the death! Nat Rev Cancer, 10, 598.

Arquier, N., L. Perrin, P. Manfruelli \& M. Semeriva (2001) The Drosophila tumor suppressor gene lethal(2)giant larvae is required for the emission of the Decapentaplegic signal. Development, 128, 2209-20.

Audebert, S., C. Navarro, C. Nourry, S. Chasserot-Golaz, P. Lecine, Y. Bellaiche, J. L. Dupont, R. T. Premont, C. Sempere, J. M. Strub, A. Van Dorsselaer, N. Vitale \& J. P. Borg (2004) Mammalian Scribble forms a tight complex with the betaPIX exchange factor. Curr Biol, 14, 987-95.

Bachmann, A., O. Kobler, R. J. Kittel, C. Wichmann, J. Sierralta, S. J. Sigrist, E. D. Gundelfinger, E. Knust \& U. Thomas (2010) A perisynaptic menage a trois between Dlg, DLin-7, and Metro controls proper organization of Drosophila synaptic junctions. J Neurosci, 30, 5811-24.

Bahri, S., S. Wang, R. Conder, J. Choy, S. Vlachos, K. Dong, C. Merino, S. Sigrist, C. Molnar, X. Yang, E. Manser \& N. Harden (2010) The leading edge during dorsal closure as a model for epithelial plasticity: Pak is required for recruitment of the Scribble complex and septate junction formation. Development, 137, 2023-32.

Beatty, A., D. Morton \& K. Kemphues (2010) The C. elegans homolog of Drosophila Lethal giant larvae functions redundantly with PAR-2 to maintain polarity in the early embryo. Development, 137, 3995-4004.

Bellaiche, Y., A. Radovic, D. F. Woods, C. D. Hough, M. L. Parmentier, C. J. O'Kane, P. J. Bryant \& F. Schweisguth (2001) The Partner of Inscuteable/Discs-large complex is required to establish planar polarity during asymmetric cell division in Drosophila. Cell, 106, 355-66.

Bernadskaya, Y. Y., F. B. Patel, H. T. Hsu \& M. C. Soto (2011) Arp2/3 promotes junction formation and maintenance in the $\mathrm{C}$. elegans intestine by regulating membrane association of apical proteins. Mol Biol Cell.

Betschinger, J., K. Mechtler \& J. A. Knoblich (2003) The Par complex directs asymmetric cell division by phosphorylating the cytoskeletal protein Lgl. Nature, 422, 32630.

Betschinger, J., K. Mechtler \& J. A. Knoblich (2006) Asymmetric segregation of the tumor suppressor brat regulates self-renewal in Drosophila neural stem cells. Cell, 124, 1241-53.

Beumer, K., H. J. Matthies, A. Bradshaw \& K. Broadie (2002) Integrins regulate DLG/FAS2 via a CaM kinase II-dependent pathway to mediate synapse elaboration and stabilization during postembryonic development. Development, 129, 3381-91. 
Bilder, D. (2001) PDZ proteins and polarity: functions from the fly. Trends Genet, 17, 511-9.

Bilder, D. (2004) Epithelial polarity and proliferation control: links from the Drosophila neoplastic tumor suppressors. Genes Dev, 18, 1909-25.

Bilder, D., M. Li \& N. Perrimon (2000) Cooperative regulation of cell polarity and growth by Drosophila tumor suppressors. Science, 289, 113-6.

Bilder, D. \& N. Perrimon (2000) Localization of apical epithelial determinants by the basolateral PDZ protein Scribble. Nature, 403, 676-80.

Bilder, D., M. Schober \& N. Perrimon (2003) Integrated activity of PDZ protein complexes regulates epithelial polarity. Nat Cell Biol, 5, 53-8.

Blankenship, J. T., M. T. Fuller \& J. A. Zallen (2007) The Drosophila homolog of the Exo84 exocyst subunit promotes apical epithelial identity. J Cell Sci, 120, 3099-110.

Botas, J. (2007) Drosophila researchers focus on human disease. Nat Genet, 39, 589-91.

Brand, A. H. \& N. Perrimon (1993) Targeted gene expression as a means of altering cell fates and generating dominant phenotypes. Development, 118, 401-15.

Brenman, J. E., J. R. Topinka, E. C. Cooper, A. W. McGee, J. Rosen, T. Milroy, H. J. Ralston \& D. S. Bredt (1998) Localization of postsynaptic density-93 to dendritic microtubules and interaction with microtubule-associated protein 1A. J Neurosci, 18, 8805-13.

Brumby, A. M., K. R. Goulding, T. Schlosser, S. Loi, R. Galea, P. Khoo, J. E. Bolden, T. Aigaki, P. O. Humbert \& H. E. Richardson (2011) Identification of Novel RasCooperating Oncogenes in Drosophila melanogaster: A RhoGEF/Rho-Family/JNK Pathway Is a Central Driver of Tumorigenesis. Genetics, 188, 105-25.

Brumby, A. M. \& H. E. Richardson (2003) scribble mutants cooperate with oncogenic Ras or Notch to cause neoplastic overgrowth in Drosophila. EMBO J, 22, 5769-79.

Brumby, A. M. \& H. E. Richardson (2005) Using Drosophila melanogaster to map human cancer pathways. Nat Rev Cancer, 5, 626-39.

Bryant, P. J. \& A. Huwe (2000) LAP proteins: what's up with epithelia? Nat Cell Biol, 2, E1413.

Budnik, V., Y. H. Koh, B. Guan, B. Hartmann, C. Hough, D. Woods \& M. Gorczyca (1996) Regulation of synapse structure and function by the Drosophila tumor suppressor gene dlg. Neuron, 17, 627-40.

Bulgakova, N. A. \& E. Knust (2009) The Crumbs complex: from epithelial-cell polarity to retinal degeneration. J Cell Sci, 122, 2587-96.

Burgess, R. W., D. L. Deitcher \& T. L. Schwarz (1997) The synaptic protein syntaxin1 is required for cellularization of Drosophila embryos. J Cell Biol, 138, 861-75.

Cachero, S. \& G. S. Jefferis (2011) Double brainbow. Nat Methods, 8, 217-8.

Caldeira, J., P. S. Pereira, G. Suriano \& F. Casares (2009) Using fruitflies to help understand the molecular mechanisms of human hereditary diffuse gastric cancer. Int J Dev Biol, 53, 1557-61.

Carr, H. S., C. Cai, K. Keinanen \& J. A. Frost (2009) Interaction of the RhoA exchange factor Net1 with discs large homolog 1 protects it from proteasome-mediated degradation and potentiates Net1 activity. J Biol Chem, 284, 24269-80.

Caussinus, E. \& C. Gonzalez (2005) Induction of tumor growth by altered stem-cell asymmetric division in Drosophila melanogaster. Nat Genet, 37, 1125-9. 
Chalmers, A. D., M. Pambos, J. Mason, S. Lang, C. Wylie \& N. Papalopulu (2005) aPKC, Crumbs3 and Lg12 control apicobasal polarity in early vertebrate development. Development, 132, 977-86.

Chen, G., W. Li, Q. S. Zhang, M. Regulski, N. Sinha, J. Barditch, T. Tully, A. R. Krainer, M. Q. Zhang \& J. Dubnau (2008) Identification of synaptic targets of Drosophila pumilio. PLoS Comput Biol, 4, e1000026.

Chen, K. \& D. E. Featherstone (2005) Discs-large (DLG) is clustered by presynaptic innervation and regulates postsynaptic glutamate receptor subunit composition in Drosophila. BMC Biol, 3, 1.

Chen, K., C. Merino, S. J. Sigrist \& D. E. Featherstone (2005) The 4.1 protein coracle mediates subunit-selective anchoring of Drosophila glutamate receptors to the postsynaptic actin cytoskeleton. J Neurosci, 25, 6667-75.

Collins, C. A. \& A. DiAntonio (2007) Synaptic development: insights from Drosophila. Curr Opin Neurobiol, 17, 35-42.

Cordero, J. B., J. P. Macagno, R. K. Stefanatos, K. E. Strathdee, R. L. Cagan \& M. Vidal (2010) Oncogenic Ras diverts a host TNF tumor suppressor activity into tumor promoter. Dev Cell, 18, 999-1011.

Courbard, J. R., A. Djiane, J. Wu \& M. Mlodzik (2009) The apical/basal-polarity determinant Scribble cooperates with the PCP core factor Stbm/Vang and functions as one of its effectors. Dev Biol, 333, 67-77.

Crnic, I. \& G. Christofori (2004) Novel technologies and recent advances in metastasis research. Int J Dev Biol, 48, 573-81.

Doerflinger, H., N. Vogt, I. L. Torres, V. Mirouse, I. Koch, C. Nusslein-Volhard \& D. St Johnston (2010) Bazooka is required for polarisation of the Drosophila anteriorposterior axis. Development, 137, 1765-73.

Dollar, G. L., U. Weber, M. Mlodzik \& S. Y. Sokol (2005) Regulation of Lethal giant larvae by Dishevelled. Nature, 437, 1376-80.

Dow, L. E., A. M. Brumby, R. Muratore, M. L. Coombe, K. A. Sedelies, J. A. Trapani, S. M. Russell, H. E. Richardson \& P. O. Humbert (2003) hScrib is a functional homologue of the Drosophila tumour suppressor Scribble. Oncogene, 22, 9225-30.

Dudu, V., P. Pantazis \& M. Gonzalez-Gaitan (2004) Membrane traffic during embryonic development: epithelial formation, cell fate decisions and differentiation. Curr Opin Cell Biol, 16, 407-14.

Duffy, H. S., I. Iacobas, K. Hotchkiss, B. J. Hirst-Jensen, A. Bosco, N. Dandachi, R. Dermietzel, P. L. Sorgen \& D. C. Spray (2007) The gap junction protein connexin32 interacts with the Src homology 3/hook domain of discs large homolog 1. J Biol Chem, 282, 9789-96.

Etienne-Manneville, S. (2009) Scribble at the crossroads. J Biol, 8, 104.

Etienne-Manneville, S. \& A. Hall (2003) Cdc42 regulates GSK-3beta and adenomatous polyposis coli to control cell polarity. Nature, 421, 753-6.

Etienne-Manneville, S., J. B. Manneville, S. Nicholls, M. A. Ferenczi \& A. Hall (2005) Cdc42 and Par6-PKCzeta regulate the spatially localized association of Dlg1 and APC to control cell polarization. J Cell Biol, 170, 895-901. 
Farkas, R., S. Kucharova-Mahmood, L. Mentelova, P. Juda, I. Raska \& B. Mechler (2011) Cytoskeletal proteins regulate chromatic access of BR-C transcription factor and Rpd3-Sin3A histone deacetylase complex in Drosophila salivary glands. Nucleus, (in print).

Farkas, R. \& B. M. Mechler (2000) The timing of drosophila salivary gland apoptosis displays an 1(2)gl-dose response. Cell Death Differ, 7, 89-101.

Fichelson, P., M. Jagut, S. Lepanse, J. A. Lepesant \& J. R. Huynh (2010) lethal giant larvae is required with the par genes for the early polarization of the Drosophila oocyte. Development, 137, 815-24.

Fischer, A., H. Stuckas, M. Gluth, T. D. Russell, M. C. Rudolph, N. E. Beeman, S. Bachmann, S. Umemura, Y. Ohashi, M. C. Neville \& F. Theuring (2007) Impaired tight junction sealing and precocious involution in mammary glands of PKN1 transgenic mice. J Cell Sci, 120, 2272-83.

Fletcher, D. A. \& R. D. Mullins (2010) Cell mechanics and the cytoskeleton. Nature, 463, 48592.

Froldi, F., M. Ziosi, F. Garoia, A. Pession, N. A. Grzeschik, P. Bellosta, D. Strand, H. E. Richardson \& D. Grifoni (2010) The lethal giant larvae tumour suppressor mutation requires dMyc oncoprotein to promote clonal malignancy. BMC Biol, 8, 33.

Froldi, F., M. Ziosi, G. Tomba, F. Parisi, F. Garoia, A. Pession \& D. Grifoni (2008) Drosophila lethal giant larvae neoplastic mutant as a genetic tool for cancer modeling. Curr Genomics, 9, 147-54.

Fuller, M. T. 1993. Spermatogenesis. Cold Spring Harbor, New York: Cold Spring Harbor Laboratory Press.

Fuller, M. T. \& A. C. Spradling (2007) Male and female Drosophila germline stem cells: two versions of immortality. Science, 316, 402-4.

Ganguly, I., T. F. Mackay \& R. R. Anholt (2003) Scribble is essential for olfactory behavior in Drosophila melanogaster. Genetics, 164, 1447-57.

Garcia-Mata, R., A. D. Dubash, L. Sharek, H. S. Carr, J. A. Frost \& K. Burridge (2007) The nuclear RhoA exchange factor Net1 interacts with proteins of the Dlg family, affects their localization, and influences their tumor suppressor activity. Mol Cell Biol, 27, 8683-97.

Gardiol, D., C. Kuhne, B. Glaunsinger, S. S. Lee, R. Javier \& L. Banks (1999) Oncogenic human papillomavirus E6 proteins target the discs large tumour suppressor for proteasome-mediated degradation. Oncogene, 18, 5487-96.

Gardiol, D., A. Zacchi, F. Petrera, G. Stanta \& L. Banks (2006) Human discs large and scrib are localized at the same regions in colon mucosa and changes in their expression patterns are correlated with loss of tissue architecture during malignant progression. Int J Cancer, 119, 1285-90.

Gateff, E. (1978) Malignant neoplasms of genetic origin in Drosophila melanogaster. Science, 200, 1448-59.

Gateff, E. \& H. A. Schneiderman (1969) Neoplasms in mutant and cultured wild-tupe tissues of Drosophila. Natl Cancer Inst Monogr, 31, 365-97.

Gateff E, S. H. (1974) Developmental capacities of benign and malignant neoplasms of Drosophila. Wilhelm Roux' Archiv, 176.

Gilbert, L. I. (2008) Drosophila is an inclusive model for human diseases, growth and development. Mol Cell Endocrinol, 293, 25-31. 
Gonzalez, C. (2007) Spindle orientation, asymmetric division and tumour suppression in Drosophila stem cells. Nat Rev Genet, 8, 462-72.

Gonzalez-Mariscal, L., R. Tapia \& D. Chamorro (2008) Crosstalk of tight junction components with signaling pathways. Biochim Biophys Acta, 1778, 729-56.

Goode, S. \& N. Perrimon (1997) Inhibition of patterned cell shape change and cell invasion by Discs large during Drosophila oogenesis. Genes Dev, 11, 2532-44.

Gorczyca, D., J. Ashley, S. Speese, N. Gherbesi, U. Thomas, E. Gundelfinger, L. S. Gramates \& V. Budnik (2007) Postsynaptic membrane addition depends on the Discs-Largeinteracting t-SNARE Gtaxin. J Neurosci, 27, 1033-44.

Grassmann, R., M. Aboud \& K. T. Jeang (2005) Molecular mechanisms of cellular transformation by HTLV-1 Tax. Oncogene, 24, 5976-85.

Graveley, B. R., A. N. Brooks, J. W. Carlson, M. O. Duff, J. M. Landolin, L. Yang, C. G. Artieri, M. J. van Baren, N. Boley, B. W. Booth, J. B. Brown, L. Cherbas, C. A. Davis, A. Dobin, R. Li, W. Lin, J. H. Malone, N. R. Mattiuzzo, D. Miller, D. Sturgill, B. B. Tuch, C. Zaleski, D. Zhang, M. Blanchette, S. Dudoit, B. Eads, R. E. Green, A. Hammonds, L. Jiang, P. Kapranov, L. Langton, N. Perrimon, J. E. Sandler, K. H. Wan, A. Willingham, Y. Zhang, Y. Zou, J. Andrews, P. J. Bickel, S. E. Brenner, M. R. Brent, P. Cherbas, T. R. Gingeras, R. A. Hoskins, T. C. Kaufman, B. Oliver \& S. E. Celniker (2011) The developmental transcriptome of Drosophila melanogaster. Nature, 471, 473-9.

Grawe, F., A. Wodarz, B. Lee, E. Knust \& H. Skaer (1996) The Drosophila genes crumbs and stardust are involved in the biogenesis of adherens junctions. Development, 122, 9519.

Gregorc, U., S. Ivanova, M. Thomas, V. Turk, L. Banks \& B. Turk (2005) hDLG/SAP97, a member of the MAGUK protein family, is a novel caspase target during cell-cell detachment in apoptosis. Biol Chem, 386, 705-10.

Grifoni, D., F. Garoia, C. C. Schimanski, G. Schmitz, E. Laurenti, P. R. Galle, A. Pession, S. Cavicchi \& D. Strand (2004) The human protein Hugl-1 substitutes for Drosophila lethal giant larvae tumour suppressor function in vivo. Oncogene, 23, 8688-94.

Grzeschik, N. A., L. M. Parsons, M. L. Allott, K. F. Harvey \& H. E. Richardson (2010a) Lgl, aPKC, and Crumbs regulate the Salvador/Warts/Hippo pathway through two distinct mechanisms. Curr Biol, 20, 573-81.

Grzeschik, N. A., L. M. Parsons \& H. E. Richardson (2010b) Lgl, the SWH pathway and tumorigenesis: It's a matter of context \& competition! Cell Cycle, 9, 3202-12.

Hadjieconomou, D., S. Rotkopf, C. Alexandre, D. M. Bell, B. J. Dickson \& I. Salecker (2011) Flybow: genetic multicolor cell labeling for neural circuit analysis in Drosophila melanogaster. Nat Methods, 8, 260-6.

Hall, W. W. \& M. Fujii (2005) Deregulation of cell-signaling pathways in HTLV-1 infection. Oncogene, 24, 5965-75.

Hamanaka, Y. \& I. A. Meinertzhagen (2010) Immunocytochemical localization of synaptic proteins to photoreceptor synapses of Drosophila melanogaster. J Comp Neurol, 518, 1133-55.

Hampel, S., P. Chung, C. E. McKellar, D. Hall, L. L. Looger \& J. H. Simpson (2011) Drosophila Brainbow: a recombinase-based fluorescence labeling technique to subdivide neural expression patterns. Nat Methods, 8, 253-9. 
Hanada, N., K. Makino, H. Koga, T. Morisaki, H. Kuwahara, N. Masuko, Y. Tabira, T. Hiraoka, N. Kitamura, A. Kikuchi \& H. Saya (2000) NE-dlg, a mammalian homolog of Drosophila dlg tumor suppressor, induces growth suppression and impairment of cell adhesion: possible involvement of down-regulation of beta-catenin by NEdlg expression. Int J Cancer, 86, 480-8.

Harris, B. Z. \& W. A. Lim (2001) Mechanism and role of PDZ domains in signaling complex assembly. J Cell Sci, 114, 3219-31.

Harris, H., O. J. Miller, G. Klein, P. Worst \& T. Tachibana (1969) Suppression of malignancy by cell fusion. Nature, 223, 363-8.

Hatsuzawa, K., H. Hirose, K. Tani, A. Yamamoto, R. H. Scheller \& M. Tagaya (2000) Syntaxin 18, a SNAP receptor that functions in the endoplasmic reticulum, intermediate compartment, and cis-Golgi vesicle trafficking. J Biol Chem, 275, 1371320.

Hering, H. \& M. Sheng (2002) Direct interaction of Frizzled-1, -2, -4, and -7 with PDZ domains of PSD-95. FEBS Lett, 521, 185-9.

Hoege, C., A. T. Constantinescu, A. Schwager, N. W. Goehring, P. Kumar \& A. A. Hyman (2010) LGL can partition the cortex of one-cell Caenorhabditis elegans embryos into two domains. Curr Biol, 20, 1296-303.

Hoffmann, M., C. Segbert, G. Helbig \& O. Bossinger (2010) Intestinal tube formation in Caenorhabditis elegans requires vang-1 and egl-15 signaling. Dev Biol, 339, 268-79.

Hsu, S. C., D. TerBush, M. Abraham \& W. Guo (2004) The exocyst complex in polarized exocytosis. Int Rev Cytol, 233, 243-65.

Humbert, P., S. Russell \& H. Richardson (2003) Dlg, Scribble and Lgl in cell polarity, cell proliferation and cancer. Bioessays, 25, 542-53.

Humbert, P. O., L. E. Dow \& S. M. Russell (2006) The Scribble and Par complexes in polarity and migration: friends or foes? Trends Cell Biol, 16, 622-30.

Humbert, P. O., N. A. Grzeschik, A. M. Brumby, R. Galea, I. Elsum \& H. E. Richardson (2008) Control of tumourigenesis by the Scribble/Dlg/Lgl polarity module. Oncogene, 27, 6888-907.

Hutterer, A., J. Betschinger, M. Petronczki \& J. A. Knoblich (2004) Sequential roles of Cdc42, Par-6, aPKC, and Lgl in the establishment of epithelial polarity during Drosophila embryogenesis. Dev Cell, 6, 845-54.

Igaki, T. (2009) Correcting developmental errors by apoptosis: lessons from Drosophila JNK signaling. Apoptosis, 14, 1021-8.

Igaki, T., R. A. Pagliarini \& T. Xu (2006) Loss of cell polarity drives tumor growth and invasion through JNK activation in Drosophila. Curr Biol, 16, 1139-46.

Ishidate, T., A. Matsumine, K. Toyoshima \& T. Akiyama (2000) The APC-hDLG complex negatively regulates cell cycle progression from the G0/G1 to S phase. Oncogene, 19, 365-72.

Ivanov, A. I., C. Young, K. Den Beste, C. T. Capaldo, P. O. Humbert, P. Brennwald, C. A. Parkos \& A. Nusrat (2010) Tumor suppressor scribble regulates assembly of tight junctions in the intestinal epithelium. Am J Pathol, 176, 134-45.

Jaekel, R. \& T. Klein (2006) The Drosophila Notch inhibitor and tumor suppressor gene lethal (2) giant discs encodes a conserved regulator of endosomal trafficking. Dev Cell, 11, 655-69. 
Jakobs, R., C. de Lorenzo, E. Spiess, D. Strand \& B. M. Mechler (1996) Homo-oligomerization domains in the lethal(2)giant larvae tumor suppressor protein, p127 of Drosophila. J Mol Biol, 264, 484-96.

Jiang, Y., K. L. Scott, S. J. Kwak, R. Chen \& G. Mardon (2011) Sds22/PP1 links epithelial integrity and tumor suppression via regulation of myosin II and JNK signaling. Oncogene.

Johnston, C. A., K. Hirono, K. E. Prehoda \& C. Q. Doe (2009) Identification of an AuroraA/PinsLINKER/Dlg spindle orientation pathway using induced cell polarity in S2 cells. Cell, 138, 1150-63.

Kallay, L. M., A. McNickle, P. J. Brennwald, A. L. Hubbard \& L. T. Braiterman (2006) Scribble associates with two polarity proteins, Lgl2 and Vangl2, via distinct molecular domains. J Cell Biochem, 99, 647-64.

Kamei, Y., K. Kito, T. Takeuchi, Y. Imai, R. Murase, N. Ueda, N. Kobayashi \& Y. Abe (2007) Human scribble accumulates in colorectal neoplasia in association with an altered distribution of beta-catenin. Hum Pathol, 38, 1273-81.

Kango-Singh, M. \& G. Halder (2004) Drosophila as an emerging model to study metastasis. Genome Biol, 5, 216.

Kaplan, N. A. \& N. S. Tolwinski (2010) Spatially defined Dsh-Lgl interaction contributes to directional tissue morphogenesis. J Cell Sci, 123, 3157-65.

Kharchenko, P. V., A. A. Alekseyenko, Y. B. Schwartz, A. Minoda, N. C. Riddle, J. Ernst, P. J. Sabo, E. Larschan, A. A. Gorchakov, T. Gu, D. Linder-Basso, A. Plachetka, G. Shanower, M. Y. Tolstorukov, L. J. Luquette, R. Xi, Y. L. Jung, R. W. Park, E. P. Bishop, T. K. Canfield, R. Sandstrom, R. E. Thurman, D. M. MacAlpine, J. A. Stamatoyannopoulos, M. Kellis, S. C. Elgin, M. I. Kuroda, V. Pirrotta, G. H. Karpen \& P. J. Park (2011) Comprehensive analysis of the chromatin landscape in Drosophila melanogaster. Nature, 471, 480-5.

Kiger, A. A., H. White-Cooper \& M. T. Fuller (2000) Somatic support cells restrict germline stem cell self-renewal and promote differentiation. Nature, 407, 750-4.

Knudson, A. G., Jr. (1971) Mutation and cancer: statistical study of retinoblastoma. Proc Natl Acad Sci U S A, 68, 820-3.

Koh, Y. H., E. Popova, U. Thomas, L. C. Griffith \& V. Budnik (1999) Regulation of DLG localization at synapses by CaMKII-dependent phosphorylation. Cell, 98, 353-63.

Langevin, J., R. Le Borgne, F. Rosenfeld, M. Gho, F. Schweisguth \& Y. Bellaiche (2005) Lethal giant larvae controls the localization of notch-signaling regulators numb, neuralized, and Sanpodo in Drosophila sensory-organ precursor cells. Curr Biol, 15, 955-62.

Laprise, P., S. M. Paul, J. Boulanger, R. M. Robbins, G. J. Beitel \& U. Tepass (2010) Epithelial polarity proteins regulate Drosophila tracheal tube size in parallel to the luminal matrix pathway. Curr Biol, 20, 55-61.

Lasserre, R. \& A. Alcover (2010) Cytoskeletal cross-talk in the control of T cell antigen receptor signaling. FEBS Lett, 584, 4845-50.

Lasserre, R., S. Charrin, C. Cuche, A. Danckaert, M. I. Thoulouze, F. de Chaumont, T. Duong, N. Perrault, N. Varin-Blank, J. C. Olivo-Marin, S. Etienne-Manneville, M. Arpin, V. Di Bartolo \& A. Alcover (2010) Ezrin tunes T-cell activation by controlling Dlg1 and microtubule positioning at the immunological synapse. EMBO J, 29, 230114. 
Lecuit, T. (2004) Junctions and vesicular trafficking during Drosophila cellularization. J Cell Sci, 117, 3427-33.

Lecuit, T. \& F. Pilot (2003) Developmental control of cell morphogenesis: a focus on membrane growth. Nat Cell Biol, 5, 103-8.

Lecuit, T. \& E. Wieschaus (2000) Polarized insertion of new membrane from a cytoplasmic reservoir during cleavage of the Drosophila embryo. J Cell Biol, 150, 849-60.

Lecuit, T. \& E. Wieschaus (2002) Junctions as organizing centers in epithelial cells? A fly perspective. Traffic, 3, 92-7.

Lee, C. Y., R. O. Andersen, C. Cabernard, L. Manning, K. D. Tran, M. J. Lanskey, A. Bashirullah \& C. Q. Doe (2006) Drosophila Aurora-A kinase inhibits neuroblast self-renewal by regulating aPKC/Numb cortical polarity and spindle orientation. Genes Dev, 20, 3464-74.

Lee, O. K., K. K. Frese, J. S. James, D. Chadda, Z. H. Chen, R. T. Javier \& K. O. Cho (2003) Discs-Large and Strabismus are functionally linked to plasma membrane formation. Nat Cell Biol, 5, 987-93.

Lee, T. \& L. Luo (2001) Mosaic analysis with a repressible cell marker (MARCM) for Drosophila neural development. Trends Neurosci, 24, 251-4.

Lelievre, S. A. (2010) Tissue polarity-dependent control of mammary epithelial homeostasis and cancer development: an epigenetic perspective. J Mammary Gland Biol Neoplasia, 15, 49-63.

Leong, G. R., K. R. Goulding, N. Amin, H. E. Richardson \& A. M. Brumby (2009) Scribble mutants promote aPKC and JNK-dependent epithelial neoplasia independently of Crumbs. BMC Biol, 7, 62.

Letizia, A., S. Sotillos, S. Campuzano \& M. Llimargas (2011) Regulated Crb accumulation controls apical constriction and invagination in Drosophila tracheal cells. J Cell Sci, 124, 240-51.

Lewis, M. J. \& H. R. Pelham (1996) SNARE-mediated retrograde traffic from the Golgi complex to the endoplasmic reticulum. Cell, 85, 205-15.

Li, M., J. Marhold, A. Gatos, I. Torok \& B. M. Mechler (2001) Differential expression of two scribble isoforms during Drosophila embryogenesis. Mech Dev, 108, 185-90.

Li, Q., S. Feng, L. Yu, G. Zhao \& M. Li (2011) Requirements of Lgl in cell differentiation and motility during Drosophila ovarian follicular epithelium morphogenesis. Fly (Austin), 5, 81-7.

Li, Q., L. Shen, T. Xin, W. Xiang, W. Chen, Y. Gao, M. Zhu, L. Yu \& M. Li (2009) Role of Scrib and Dlg in anterior-posterior patterning of the follicular epithelium during Drosophila oogenesis. BMC Dev Biol, 9, 60.

Li, Q., T. Xin, W. Chen, M. Zhu \& M. Li (2008) Lethal(2)giant larvae is required in the follicle cells for formation of the initial AP asymmetry and the oocyte polarity during Drosophila oogenesis. Cell Res, 18, 372-84.

Lighthouse, D. V., M. Buszczak \& A. C. Spradling (2008) New components of the Drosophila fusome suggest it plays novel roles in signaling and transport. Dev Biol, 317, 59-71.

Lin, H. (2002) The stem-cell niche theory: lessons from flies. Nat Rev Genet, 3, 931-40.

Liu, H., L. Golebiewski, E. C. Dow, R. M. Krug, R. T. Javier \& A. P. Rice (2010a) The ESEV PDZ-binding motif of the avian influenza A virus NS1 protein protects infected cells from apoptosis by directly targeting Scribble. J Virol, 84, 11164-74. 
Liu, Z., Y. Chen, D. Wang, S. Wang \& Y. Q. Zhang (2010b) Distinct presynaptic and postsynaptic dismantling processes of Drosophila neuromuscular junctions during metamorphosis. J Neurosci, 30, 11624-34.

Lozovatsky, L., N. Abayasekara, S. Piawah \& Z. Walther (2009) CASK deletion in intestinal epithelia causes mislocalization of LIN7C and the DLG1/Scrib polarity complex without affecting cell polarity. Mol Biol Cell, 20, 4489-99.

Mahoney, Z. X., B. Sammut, R. J. Xavier, J. Cunningham, G. Go, K. L. Brim, T. S. Stappenbeck, J. H. Miner \& W. Swat (2006) Discs-large homolog 1 regulates smooth muscle orientation in the mouse ureter. Proc Natl Acad Sci U S A, 103, 19872-7.

Mair, W. (2010) How normal cells can win the battle for survival against cancer cells. PLoS Biol, 8, e1000423.

Manfruelli, P., N. Arquier, W. P. Hanratty \& M. Semeriva (1996) The tumor suppressor gene, lethal(2)giant larvae (1(2)g1), is required for cell shape change of epithelial cells during Drosophila development. Development, 122, 2283-94.

Manneville, J. B., M. Jehanno \& S. Etienne-Manneville (2010) Dlg1 binds GKAP to control dynein association with microtubules, centrosome positioning, and cell polarity. $J$ Cell Biol, 191, 585-98.

Mao, P., Y. X. Tao, M. Fukaya, F. Tao, D. Li, M. Watanabe \& R. A. Johns (2008) Cloning and characterization of E-dlg, a novel splice variant of mouse homologue of the Drosophila discs large tumor suppressor binds preferentially to SAP102. IUBMB Life, 60, 684-92.

Mathew, D., L. S. Gramates, M. Packard, U. Thomas, D. Bilder, N. Perrimon, M. Gorczyca \& V. Budnik (2002) Recruitment of scribble to the synaptic scaffolding complex requires GUK-holder, a novel DLG binding protein. Curr Biol, 12, 531-9.

Matsumine, A., A. Ogai, T. Senda, N. Okumura, K. Satoh, G. H. Baeg, T. Kawahara, S. Kobayashi, M. Okada, K. Toyoshima \& T. Akiyama (1996) Binding of APC to the human homolog of the Drosophila discs large tumor suppressor protein. Science, 272, 1020-3.

Mazumdar, A. \& M. Mazumdar (2002) How one becomes many: blastoderm cellularization in Drosophila melanogaster. Bioessays, 24, 1012-22.

Mechler, B. M., W. McGinnis \& W. J. Gehring (1985) Molecular cloning of lethal(2)giant larvae, a recessive oncogene of Drosophila melanogaster. EMBO J, 4, 1551-7.

Menendez, J., A. Perez-Garijo, M. Calleja \& G. Morata (2010) A tumor-suppressing mechanism in Drosophila involving cell competition and the Hippo pathway. Proc Natl Acad Sci U S A, 107, 14651-6.

Merz, R., M. Schmidt, I. Torok, U. Protin, G. Schuler, H. P. Walther, F. Krieg, M. Gross, D. Strand \& B. M. Mechler (1990) Molecular action of the 1(2)gl tumor suppressor gene of Drosophila melanogaster. Environ Health Perspect, 88, 163-7.

Mohamet, L., K. Hawkins \& C. M. Ward (2011) Loss of function of e-cadherin in embryonic stem cells and the relevance to models of tumorigenesis. J Oncol, 2011, 352616.

Momboisse, F., E. Lonchamp, V. Calco, M. Ceridono, N. Vitale, M. F. Bader \& S. Gasman (2009) betaPIX-activated Rac1 stimulates the activation of phospholipase D, which is associated with exocytosis in neuroendocrine cells. J Cell Sci, 122, 798-806.

Montcouquiol, M., R. A. Rachel, P. J. Lanford, N. G. Copeland, N. A. Jenkins \& M. W. Kelley (2003) Identification of Vangl2 and Scrb1 as planar polarity genes in mammals. Nature, 423, 173-7. 
Montcouquiol, M., N. Sans, D. Huss, J. Kach, J. D. Dickman, A. Forge, R. A. Rachel, N. G. Copeland, N. A. Jenkins, D. Bogani, J. Murdoch, M. E. Warchol, R. J. Wenthold \& M. W. Kelley (2006) Asymmetric localization of Vangl2 and Fz3 indicate novel mechanisms for planar cell polarity in mammals. J Neurosci, 26, 5265-75.

Moreau, M. M., N. Piguel, T. Papouin, M. Koehl, C. M. Durand, M. E. Rubio, F. Loll, E. M. Richard, C. Mazzocco, C. Racca, S. H. Oliet, D. N. Abrous, M. Montcouquiol \& N. Sans (2010) The planar polarity protein Scribble1 is essential for neuronal plasticity and brain function. J Neurosci, 30, 9738-52.

Morimoto, T., M. Nobechi, A. Komatsu, H. Miyakawa \& A. Nose (2010) Subunit-specific and homeostatic regulation of glutamate receptor localization by CaMKII in Drosophila neuromuscular junctions. Neuroscience, 165, 1284-92.

Musch, A., D. Cohen, C. Yeaman, W. J. Nelson, E. Rodriguez-Boulan \& P. J. Brennwald (2002) Mammalian homolog of Drosophila tumor suppressor lethal (2) giant larvae interacts with basolateral exocytic machinery in Madin-Darby canine kidney cells. Mol Biol Cell, 13, 158-68.

Nakagawa, S. \& J. M. Huibregtse (2000) Human scribble (Vartul) is targeted for ubiquitinmediated degradation by the high-risk papillomavirus E6 proteins and the E6AP ubiquitin-protein ligase. Mol Cell Biol, 20, 8244-53.

Nakagawa, S., T. Yano, K. Nakagawa, S. Takizawa, Y. Suzuki, T. Yasugi, J. M. Huibregtse \& Y. Taketani (2004) Analysis of the expression and localisation of a LAP protein, human scribble, in the normal and neoplastic epithelium of uterine cervix. $\mathrm{Br} \mathrm{J}$ Cancer, 90, 194-9.

Namdarian, B., E. Wong, R. Galea, J. Pedersen, X. Chin, R. Speirs, P. O. Humbert, A. J. Costello, N. M. Corcoran \& C. M. Hovens (2011) Loss of APKC expression independently predicts tumor recurrence in superficial bladder cancers. Urol Oncol.

Navarro, C., S. Nola, S. Audebert, M. J. Santoni, J. P. Arsanto, C. Ginestier, S. Marchetto, J. Jacquemier, D. Isnardon, A. Le Bivic, D. Birnbaum \& J. P. Borg (2005) Junctional recruitment of mammalian Scribble relies on E-cadherin engagement. Oncogene, 24, 4330-9.

Negre, N., C. D. Brown, L. Ma, C. A. Bristow, S. W. Miller, U. Wagner, P. Kheradpour, M. L. Eaton, P. Loriaux, R. Sealfon, Z. Li, H. Ishii, R. F. Spokony, J. Chen, L. Hwang, C. Cheng, R. P. Auburn, M. B. Davis, M. Domanus, P. K. Shah, C. A. Morrison, J. Zieba, S. Suchy, L. Senderowicz, A. Victorsen, N. A. Bild, A. J. Grundstad, D. Hanley, D. M. MacAlpine, M. Mannervik, K. Venken, H. Bellen, R. White, M. Gerstein, S. Russell, R. L. Grossman, B. Ren, J. W. Posakony, M. Kellis \& K. P. White (2011) A cis-regulatory map of the Drosophila genome. Nature, 471, 527-31.

Nguyen, M. M., C. Rivera \& A. E. Griep (2005) Localization of PDZ domain containing proteins Discs Large-1 and Scribble in the mouse eye. Mol Vis, 11, 1183-99.

Niethammer, M., J. G. Valtschanoff, T. M. Kapoor, D. W. Allison, R. J. Weinberg, A. M. Craig \& M. Sheng (1998) CRIPT, a novel postsynaptic protein that binds to the third PDZ domain of PSD-95/SAP90. Neuron, 20, 693-707.

Ohsawa, S., K. Sugimura, K. Takino, T. Xu, A. Miyawaki \& T. Igaki (2011) Elimination of oncogenic neighbors by JNK-mediated engulfment in Drosophila. Dev Cell, 20, 31528. 
Okajima, M., M. Takahashi, M. Higuchi, T. Ohsawa, S. Yoshida, Y. Yoshida, M. Oie, Y. Tanaka, F. Gejyo \& M. Fujii (2008) Human T-cell leukemia virus type 1 Tax induces an aberrant clustering of the tumor suppressor Scribble through the PDZ domain-binding motif dependent and independent interaction. Virus Genes, 37, 231-40.

Osmani, N., N. Vitale, J. P. Borg \& S. Etienne-Manneville (2006) Scrib controls Cdc42 localization and activity to promote cell polarization during astrocyte migration. Curr Biol, 16, 2395-405.

Ouyang, Z., W. Zhan \& L. Dan (2010) hScrib, a human homolog of Drosophila neoplastic tumor suppressor, is involved in the progress of endometrial cancer. Oncol Res, 18, 593-9.

Pagliarini, R. A. \& T. Xu (2003) A genetic screen in Drosophila for metastatic behavior. Science, 302, 1227-31.

Papagiannouli, F. 2003. Gonad formation in discs-large and scribble mutant embryos and larvae of Drosophila melanogaster. In Combined Faculties for the Natural Sciences and Mathematics, p. 1-120. Heidelberg: Ruperto-Carola, University of Heidelberg.

Papagiannouli, F. \& B. M. Mechler (2009) discs large regulates somatic cyst cell survival and expansion in Drosophila testis. Cell Res, 19, 1139-49.

Papagiannouli, F. \& B. M. Mechler (2010) discs large in the Drosophila testis: An old player on a new task. Fly (Austin), 4.

Patel, S. K., F. E. Indig, N. Olivieri, N. D. Levine \& M. Latterich (1998) Organelle membrane fusion: a novel function for the syntaxin homolog Ufe1p in ER membrane fusion. Cell, 92, 611-20.

Paul, S. M., M. Ternet, P. M. Salvaterra \& G. J. Beitel (2003) The Na+/K+ ATPase is required for septate junction function and epithelial tube-size control in the Drosophila tracheal system. Development, 130, 4963-74.

Pelissier, A., J. P. Chauvin \& T. Lecuit (2003) Trafficking through Rab11 endosomes is required for cellularization during Drosophila embryogenesis. Curr Biol, 13, 184857.

Petit, M. M., S. M. Meulemans, P. Alen, T. A. Ayoubi, E. Jansen \& W. J. Van de Ven (2005) The tumor suppressor Scrib interacts with the zyxin-related protein LPP, which shuttles between cell adhesion sites and the nucleus. BMC Cell Biol, 6, 1.

Pfleger, C. M. \& L. T. Reiter (2008) Recent efforts to model human diseases in vivo in Drosophila. Fly (Austin), 2, 129-32.

Phillips, H. M., H. J. Rhee, J. N. Murdoch, V. Hildreth, J. D. Peat, R. H. Anderson, A. J. Copp, B. Chaudhry \& D. J. Henderson (2007) Disruption of planar cell polarity signaling results in congenital heart defects and cardiomyopathy attributable to early cardiomyocyte disorganization. Circ Res, 101, 137-45.

Plant, P. J., J. P. Fawcett, D. C. Lin, A. D. Holdorf, K. Binns, S. Kulkarni \& T. Pawson (2003) A polarity complex of mPar-6 and atypical PKC binds, phosphorylates and regulates mammalian Lgl. Nat Cell Biol, 5, 301-8.

Potter, C. J., B. Tasic, E. V. Russler, L. Liang \& L. Luo (2010) The Q system: a repressible binary system for transgene expression, lineage tracing, and mosaic analysis. Cell, $141,536-48$. 
Qin, Y., C. Capaldo, B. M. Gumbiner \& I. G. Macara (2005) The mammalian Scribble polarity protein regulates epithelial cell adhesion and migration through E-cadherin. J Cell Biol, 171, 1061-71.

Reischauer, S., M. P. Levesque, C. Nusslein-Volhard \& M. Sonawane (2009) Lgl2 executes its function as a tumor suppressor by regulating ErbB signaling in the zebrafish epidermis. PLoS Genet, 5, e1000720.

Reiter, L. T., L. Potocki, S. Chien, M. Gribskov \& E. Bier (2001) A systematic analysis of human disease-associated gene sequences in Drosophila melanogaster. Genome Res, 11, 1114-25.

Riggs, B., W. Rothwell, S. Mische, G. R. Hickson, J. Matheson, T. S. Hays, G. W. Gould \& W. Sullivan (2003) Actin cytoskeleton remodeling during early Drosophila furrow formation requires recycling endosomal components Nuclear-fallout and Rab11. J Cell Biol, 163, 143-54.

Rivera, C., I. F. Yamben, S. Shatadal, M. Waldof, M. L. Robinson \& A. E. Griep (2009) Cellautonomous requirements for Dlg-1 for lens epithelial cell structure and fiber cell morphogenesis. Dev Dyn, 238, 2292-308.

Roche, J. P., M. C. Packard, S. Moeckel-Cole \& V. Budnik (2002) Regulation of synaptic plasticity and synaptic vesicle dynamics by the PDZ protein Scribble. J Neurosci, 22, 6471-9.

Rossi, G. \& P. Brennwald (2011) Yeast homologues of lethal giant larvae and type V myosin cooperate in the regulation of Rab-dependent vesicle clustering and polarized exocytosis. Mol Biol Cell, 22, 842-57.

Round, J. L., L. A. Humphries, T. Tomassian, P. Mittelstadt, M. Zhang \& M. C. Miceli (2007) Scaffold protein Dlgh1 coordinates alternative p38 kinase activation, directing $\mathrm{T}$ cell receptor signals toward NFAT but not NF-kappaB transcription factors. Nat Immunol, 8, 154-61.

Sarkar, A., N. Parikh, S. A. Hearn, M. T. Fuller, S. I. Tazuke \& C. Schulz (2007) Antagonistic roles of Rac and Rho in organizing the germ cell microenvironment. Curr Biol, 17, 1253-8.

Savory, J. G., M. Mansfield, F. M. Rijli \& D. Lohnes (2011) Cdx mediates neural tube closure through transcriptional regulation of the planar cell polarity gene Ptk7. Development, 138, 1361-70.

Schmeichel, K. L. (2004) A fly's eye view of tumor progression and metastasis. Breast Cancer Res, 6, 82-3.

Schuster, C. M., G. W. Davis, R. D. Fetter \& C. S. Goodman (1996a) Genetic dissection of structural and functional components of synaptic plasticity. I. Fasciclin II controls synaptic stabilization and growth. Neuron, 17, 641-54.

Schuster, C. M., G. W. Davis, R. D. Fetter \& C. S. Goodman (1996b) Genetic dissection of structural and functional components of synaptic plasticity. II. Fasciclin II controls presynaptic structural plasticity. Neuron, 17, 655-67.

Siegrist, S. E. \& C. Q. Doe (2005) Microtubule-induced Pins/Galphai cortical polarity in Drosophila neuroblasts. Cell, 123, 1323-35.

Skouloudaki, K., M. Puetz, M. Simons, J. R. Courbard, C. Boehlke, B. Hartleben, C. Engel, M. J. Moeller, C. Englert, F. Bollig, T. Schafer, H. Ramachandran, M. Mlodzik, T. B. Huber, E. W. Kuehn, E. Kim, A. Kramer-Zucker \& G. Walz (2009) Scribble participates in Hippo signaling and is required for normal zebrafish pronephros development. Proc Natl Acad Sci U S A, 106, 8579-84. 
Sonawane, M., Y. Carpio, R. Geisler, H. Schwarz, H. M. Maischein \& C. Nuesslein-Volhard (2005) Zebrafish penner/lethal giant larvae 2 functions in hemidesmosome formation, maintenance of cellular morphology and growth regulation in the developing basal epidermis. Development, 132, 3255-65.

Sonawane, M., H. Martin-Maischein, H. Schwarz \& C. Nusslein-Volhard (2009) Lgl2 and Ecadherin act antagonistically to regulate hemidesmosome formation during epidermal development in zebrafish. Development, 136, 1231-40.

Sripathy, S., M. Lee \& V. Vasioukhin (2011) Mammalian Llgl2 is necessary for proper branching morphogenesis during placental development. Mol Cell Biol.

Strand, D., R. Jakobs, G. Merdes, B. Neumann, A. Kalmes, H. W. Heid, I. Husmann \& B. M. Mechler (1994a) The Drosophila lethal(2)giant larvae tumor suppressor protein forms homo-oligomers and is associated with nonmuscle myosin II heavy chain. J Cell Biol, 127, 1361-73.

Strand, D., I. Raska \& B. M. Mechler (1994b) The Drosophila lethal(2)giant larvae tumor suppressor protein is a component of the cytoskeleton. J Cell Biol, 127, 1345-60.

Strickland, L. I. \& D. R. Burgess (2004) Pathways for membrane trafficking during cytokinesis. Trends Cell Biol, 14, 115-8.

Suresh, B., S. Ramakrishna, Y. S. Kim, S. M. Kim, M. S. Kim \& K. H. Baek (2010) Stability and function of mammalian lethal giant larvae-1 oncoprotein are regulated by the scaffolding protein RanBPM. J Biol Chem, 285, 35340-9.

Swanson, L. E. \& G. J. Beitel (2006) Tubulogenesis: an inside job. Curr Biol, 16, R51-3.

Takizawa, S., K. Nagasaka, S. Nakagawa, T. Yano, K. Nakagawa, T. Yasugi, T. Takeuchi, T. Kanda, J. M. Huibregtse, T. Akiyama \& Y. Taketani (2006) Human scribble, a novel tumor suppressor identified as a target of high-risk HPV E6 for ubiquitin-mediated degradation, interacts with adenomatous polyposis coli. Genes Cells, 11, 453-64.

Tamori, Y., C. U. Bialucha, A. G. Tian, M. Kajita, Y. C. Huang, M. Norman, N. Harrison, J. Poulton, K. Ivanovitch, L. Disch, T. Liu, W. M. Deng \& Y. Fujita (2010) Involvement of Lgl and Mahjong/VprBP in cell competition. PLoS Biol, 8, e1000422.

Tanentzapf, G. \& U. Tepass (2003) Interactions between the crumbs, lethal giant larvae and bazooka pathways in epithelial polarization. Nat Cell Biol, 5, 46-52.

Tapon, N. (2003) Modeling transformation and metastasis in Drosophila. Cancer Cell, 4, 3335.

Thomas, U., S. Ebitsch, M. Gorczyca, Y. H. Koh, C. D. Hough, D. Woods, E. D. Gundelfinger \& V. Budnik (2000) Synaptic targeting and localization of discs-large is a stepwise process controlled by different domains of the protein. Curr Biol, 10, 1108-17.

Thomas, U., E. Kim, S. Kuhlendahl, Y. H. Koh, E. D. Gundelfinger, M. Sheng, C. C. Garner \& V. Budnik (1997a) Synaptic clustering of the cell adhesion molecule fasciclin II by discs-large and its role in the regulation of presynaptic structure. Neuron, 19, 78799.

Thomas, U., B. Phannavong, B. Muller, C. C. Garner \& E. D. Gundelfinger (1997b) Functional expression of rat synapse-associated proteins SAP97 and SAP102 in Drosophila dlg-1 mutants: effects on tumor suppression and synaptic bouton structure. Mech Dev, 62, 161-74.

Tomaic, V., D. Pim \& L. Banks (2009) The stability of the human papillomavirus E6 oncoprotein is E6AP dependent. Virology, 393, 7-10. 
Tran, J., T. J. Brenner \& S. DiNardo (2000) Somatic control over the germline stem cell lineage during Drosophila spermatogenesis. Nature, 407, 754-7.

Vaira, V., A. Faversani, T. Dohi, M. Maggioni, M. Nosotti, D. Tosi, D. C. Altieri \& S. Bosari (2011) Aberrant Overexpression of the Cell Polarity Module Scribble in Human Cancer. Am J Pathol.

Vasioukhin, V. (2006) Lethal giant puzzle of Lgl. Dev Neurosci, 28, 13-24.

Vidal, M. (2010) The dark side of fly TNF: an ancient developmental proof reading mechanism turned into tumor promoter. Cell Cycle, 9, 3851-6.

Vidal, M., L. Salavaggione, L. Ylagan, M. Wilkins, M. Watson, K. Weilbaecher \& R. Cagan (2010) A role for the epithelial microenvironment at tumor boundaries: evidence from Drosophila and human squamous cell carcinomas. Am J Pathol, 176, 3007-14.

Vieira, V., G. de la Houssaye, E. Lacassagne, J. L. Dufier, J. P. Jais, F. Beermann, M. Menasche \& M. Abitbol (2008) Differential regulation of Dlg1, Scrib, and Lg11 expression in a transgenic mouse model of ocular cancer. Mol Vis, 14, 2390-403.

Walsh, G. S., P. K. Grant, J. A. Morgan \& C. B. Moens (2011) Planar polarity pathway and Nance-Horan syndrome-like $1 \mathrm{~b}$ have essential cell-autonomous functions in neuronal migration. Development, 138, 3033-42.

Wang, S., S. A. Jayaram, J. Hemphala, K. A. Senti, V. Tsarouhas, H. Jin \& C. Samakovlis (2006) Septate-junction-dependent luminal deposition of chitin deacetylases restricts tube elongation in the Drosophila trachea. Curr Biol, 16, 180-5.

Wansleeben, C., L. van Gurp, H. Feitsma, C. Kroon, E. Rieter, M. Verberne, V. Guryev, E. Cuppen \& F. Meijlink (2011) An ENU-Mutagenesis Screen in the Mouse: Identification of Novel Developmental Gene Functions. PLoS One, 6, e19357.

Weiss, P. 1961. In The Molecular Control of Cellular Activity, ed. A. JM, pp. 1-72.: McGrawHill.

Wen, S., H. Zhu, W. Lu, L. E. Mitchell, G. M. Shaw, E. J. Lammer \& R. H. Finnell (2010) Planar cell polarity pathway genes and risk for spina bifida. Am J Med Genet A, 152A, 299-304.

Wirtz-Peitz, F. \& J. A. Knoblich (2006) Lethal giant larvae take on a life of their own. Trends Cell Biol, 16, 234-41.

Wodarz, A. (2000) Tumor suppressors: linking cell polarity and growth control. Curr Biol, 10, R624-6.

Wodarz, A. \& C. Gonzalez (2006) Connecting cancer to the asymmetric division of stem cells. Cell, 124, 1121-3.

Wodarz, A., U. Hinz, M. Engelbert \& E. Knust (1995) Expression of crumbs confers apical character on plasma membrane domains of ectodermal epithelia of Drosophila. Cell, 82, 67-76.

Wong, M. D., Z. Jin \& T. Xie (2005) Molecular mechanisms of germline stem cell regulation. Annu Rev Genet, 39, 173-95.

Woodhouse, E. C. \& L. A. Liotta (2004) Drosophila invasive tumors: a model for understanding metastasis. Cell Cycle, 3, 38-40.

Woods, D. F., C. Hough, D. Peel, G. Callaini \& P. J. Bryant (1996) Dlg protein is required for junction structure, cell polarity, and proliferation control in Drosophila epithelia. J Cell Biol, 134, 1469-82.

Wu, J. S. \& L. Luo (2006) A protocol for mosaic analysis with a repressible cell marker (MARCM) in Drosophila. Nat Protoc, 1, 2583-9. 
Wu, M., J. C. Pastor-Pareja \& T. Xu (2010) Interaction between Ras(V12) and scribbled clones induces tumour growth and invasion. Nature, 463, 545-8.

Wu, V. M. \& G. J. Beitel (2004) A junctional problem of apical proportions: epithelial tubesize control by septate junctions in the Drosophila tracheal system. Curr Opin Cell Biol, 16, 493-9.

Yamanaka, T., Y. Horikoshi, N. Izumi, A. Suzuki, K. Mizuno \& S. Ohno (2006) Lgl mediates apical domain disassembly by suppressing the PAR-3-aPKC-PAR-6 complex to orient apical membrane polarity. J Cell Sci, 119, 2107-18.

Yamanaka, T., Y. Horikoshi, Y. Sugiyama, C. Ishiyama, A. Suzuki, T. Hirose, A. Iwamatsu, A. Shinohara \& S. Ohno (2003) Mammalian Lgl forms a protein complex with PAR6 and aPKC independently of PAR-3 to regulate epithelial cell polarity. Curr Biol, $13,734-43$.

Yamanaka, T. \& S. Ohno (2008) Role of $\mathrm{Lgl} / \mathrm{Dlg} /$ Scribble in the regulation of epithelial junction, polarity and growth. Front Biosci, 13, 6693-707.

Yamashita, Y. M., A. P. Mahowald, J. R. Perlin \& M. T. Fuller (2007) Asymmetric inheritance of mother versus daughter centrosome in stem cell division. Science, 315, 518-21.

Yates, L. L., J. Papakrivopoulou, D. A. Long, P. Goggolidou, J. O. Connolly, A. S. Woolf \& C. H. Dean (2010a) The planar cell polarity gene Vangl2 is required for mammalian kidney-branching morphogenesis and glomerular maturation. Hum Mol Genet, 19, 4663-76.

Yates, L. L., C. Schnatwinkel, J. N. Murdoch, D. Bogani, C. J. Formstone, S. Townsend, A. Greenfield, L. A. Niswander \& C. H. Dean (2010b) The PCP genes Celsr1 and Vangl2 are required for normal lung branching morphogenesis. Hum Mol Genet, 19, 2251-67.

Zarnescu, D. C., P. Jin, J. Betschinger, M. Nakamoto, Y. Wang, T. C. Dockendorff, Y. Feng, T. A. Jongens, J. C. Sisson, J. A. Knoblich, S. T. Warren \& K. Moses (2005) Fragile $\mathrm{X}$ protein functions with lgl and the par complex in flies and mice. Dev Cell, 8, 4352.

Zeng, X., S. R. Singh, D. Hou \& S. X. Hou (2010) Tumor suppressors Sav/Scrib and oncogene Ras regulate stem-cell transformation in adult Drosophila malpighian tubules. J Cell Physiol, 224, 766-74.

Zhan, L., A. Rosenberg, K. C. Bergami, M. Yu, Z. Xuan, A. B. Jaffe, C. Allred \& S. K. Muthuswamy (2008) Deregulation of scribble promotes mammary tumorigenesis and reveals a role for cell polarity in carcinoma. Cell, 135, 865-78.

Zhang, X., P. Wang, A. Gangar, J. Zhang, P. Brennwald, D. TerBush \& W. Guo (2005) Lethal giant larvae proteins interact with the exocyst complex and are involved in polarized exocytosis. J Cell Biol, 170, 273-83.

Zhang, Y., H. Guo, H. Kwan, J. W. Wang, J. Kosek \& B. Lu (2007) PAR-1 kinase phosphorylates Dlg and regulates its postsynaptic targeting at the Drosophila neuromuscular junction. Neuron, 53, 201-15.

Zhu, M., T. Xin, S. Weng, Y. Gao, Y. Zhang, Q. Li \& M. Li (2010) Activation of JNK signaling links lgl mutations to disruption of the cell polarity and epithelial organization in Drosophila imaginal discs. Cell Res, 20, 242-5.

Zigman, M., A. Trinh le, S. E. Fraser \& C. B. Moens (2011) Zebrafish neural tube morphogenesis requires Scribble-dependent oriented cell divisions. Curr Biol, 21, 79-86. 
Zito, K., R. D. Fetter, C. S. Goodman \& E. Y. Isacoff (1997) Synaptic clustering of Fascilin II and Shaker: essential targeting sequences and role of Dlg. Neuron, 19, 1007-16. 


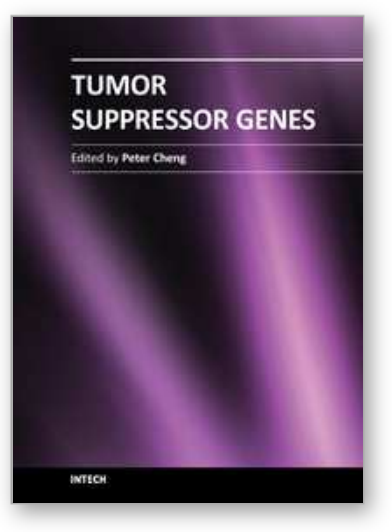

\author{
Tumor Suppressor Genes \\ Edited by Dr. Yue Cheng
}

ISBN 978-953-307-879-3

Hard cover, 332 pages

Publisher InTech

Published online 03, February, 2012

Published in print edition February, 2012

Functional evidence obtained from somatic cell fusion studies indicated that a group of genes from normal cells might replace or correct a defective function of cancer cells. Tumorigenesis that could be initiated by two mutations was established by the analysis of hereditary retinoblastoma, which led to the eventual cloning of RB1 gene. The two-hit hypothesis helped isolate many tumor suppressor genes (TSG) since then. More recently, the roles of haploinsufficiency, epigenetic control, and gene dosage effects in some TSGs, such as P53, P16 and PTEN, have been studied extensively. It is now widely recognized that deregulation of growth control is one of the major hallmarks of cancer biological capabilities, and TSGs play critical roles in many cellular activities through signaling transduction networks. This book is an excellent review of current understanding of TSGs, and indicates that the accumulated TSG knowledge has opened a new frontier for cancer therapies.

\title{
How to reference
}

In order to correctly reference this scholarly work, feel free to copy and paste the following:

Fani Papagiannouli and Bernard M. Mechler (2012). Refining the role of Lgl, Dlg and Scrib in Tumor Suppression and Beyond: Learning from the Old Time Classics, Tumor Suppressor Genes, Dr. Yue Cheng (Ed.), ISBN: 978-953-307-879-3, InTech, Available from: http://www.intechopen.com/books/tumor-suppressorgenes/refining-the-role-of-lgl-dlg-and-scrib-in-tumor-suppression-and-beyond-learning-from-the-old-time-cl

\section{INTECH}

open science | open minds

\author{
InTech Europe \\ University Campus STeP Ri \\ Slavka Krautzeka 83/A \\ 51000 Rijeka, Croatia \\ Phone: +385 (51) 770447 \\ Fax: +385 (51) 686166 \\ www.intechopen.com
}

\author{
InTech China \\ Unit 405, Office Block, Hotel Equatorial Shanghai \\ No.65, Yan An Road (West), Shanghai, 200040, China \\ 中国上海市延安西路65号上海国际贵都大饭店办公楼 405 单元 \\ Phone: +86-21-62489820 \\ Fax: $+86-21-62489821$
}


(C) 2012 The Author(s). Licensee IntechOpen. This is an open access article distributed under the terms of the Creative Commons Attribution 3.0 License, which permits unrestricted use, distribution, and reproduction in any medium, provided the original work is properly cited. 